\title{
ممارسات الإستخدام وطرق العناية بأقمشة غرفة المعيشة لاى عينة من السيدات بمدينة الإسكندرية
}

\author{
سونيا محمد عبد المحسن شيبون \\ أستاذ مساعد ملابس ونسيج - قسم الإقتصاد المنزلى - كلية الزر اعة- جامعة الإسكندرية \\ الملخص
}

أستهدف هذا البحث دراسة ممارسات الإستخدام وطرق العناية بأقمشة تتجيد غرفة المعيثة لدى عينة من السبدات بمدينة الإسكندرية

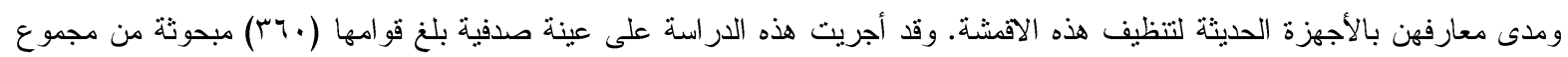

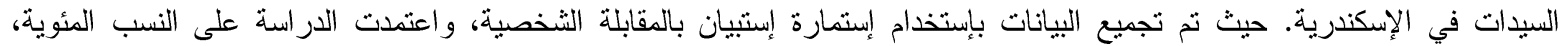

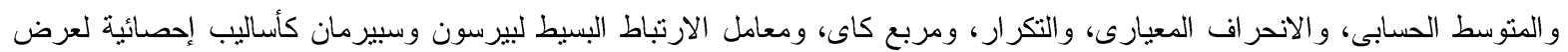

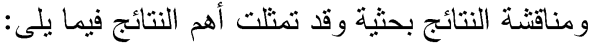

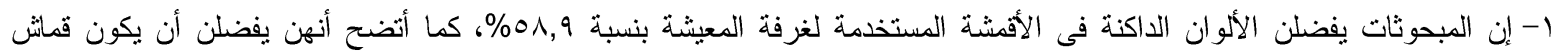

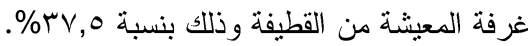
r- إنخفاض مستوى ممارسات المبحوثات لكلا من الإستخدام وطرق العناية وإجمالى الممارسات لأفشة تتجيد غرف المعيشة، كذلك إنخفاض مستوى معارفهن عن أجهزة العناية المناسبة.

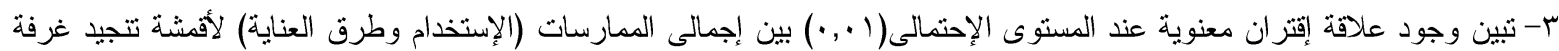

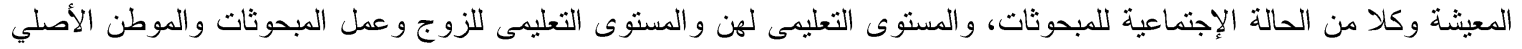

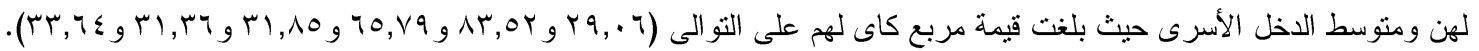
ع-وكما تبين أن هناك إقتران بين كل من معارف المبحوثات عن أجهزة العناية لأقمشة تتجيد غرف المعيشة وبين الحالة الإجتماعية

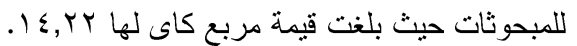
ه-وجود علاقة إرتباط شديدة المعنوية عند ا.,.• بين إجمالى ممارسات (الاستخدام وطرق العناية)لأقمشة تتجيد غرفة المعيشة وكلا من

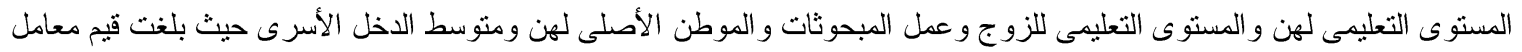

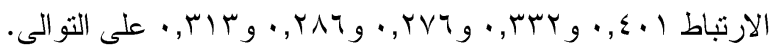
1-كما وجدت علاقة ارتباطية طردية معنوية عند ه ., · بين إجمالى ممارسات (الاستخدام وطرق العناية) الأقفشة تنجيد غرفة المعيشة وكلا

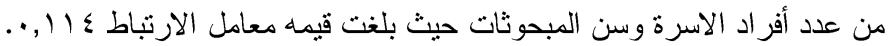
الكلمات المفتاحية: أقشة التنجيد، غرفة المعيشة، طرق العناية لأقمشة التنجيد. و المساند و الأغطية و الوسائد كالبطانة و الحشو، سامية المقدمة

$$
\text { لطفى (r... (r. ) }
$$

ويعتبر قماش التنجيد العامل الأساسى فى تصميم قطعة الأثاث و غالباً ما يحدد وبشكل كبير الأسلوب

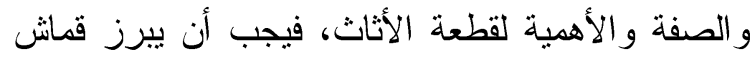
التتجيد جمالها ويناسبها ولا يتعارض مع والهيه وظيفتها،

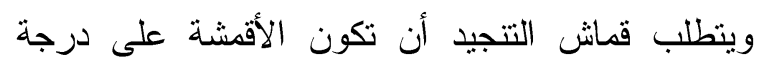
عالية من المتانة كى تتحمل الإستعمال وكذلك مقاومتها

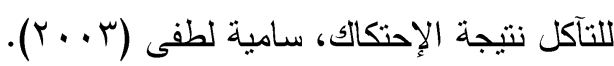

تشتمل المفروشات على جميع الأقمشة و المنسوجات التى يتعامل معها الإنسان فى ظروفه العادية غير الملابس ،وبذللك فإنها تحتوى على جميع مفروشات المنزل من مفارش آسرة وملاءات وأغطية آسرة

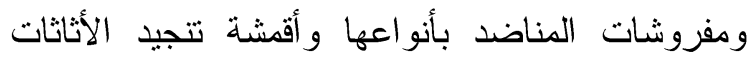
بالإضافة الى مفروشات الأرضية و المشايات و الفوط بأنواعها المختلفة وتصميماتها المتعددة بجانب الستائر 
كما أن التظظيف بالبخار و إستخدام المكنسة الكهربائية يؤدى إلى إنخفاض كبير فى مسببات الحساسية لعث غبار السجاد والأثاث المنجد بالمقارنة بالكنس المكثف العادى، مما يدل على أن التدخلات

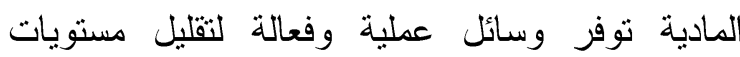
مسبيات الحساسية لعث غبار المنزل فى البيئات

الحضرية،،(Vojta etal, 2001).

إن أجهزة التتظيف بالبخار مفيدة حتى يعمل التنظف

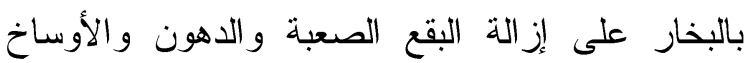
ويعقم الأسطح ويزيل المواد المسبية للحساسية ويقتل البكتيريا و العفن و الفيروسات وعث التزاب وحشرة الفراش ومعظم البكتبريا المسبية لأمر اض أيضًا

.(Mark Spelma,2019)

\section{المشكلة البحثية}

مما سبق يتضح الدور الحيوى الذى يلعبة الأثاث

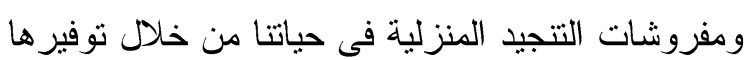

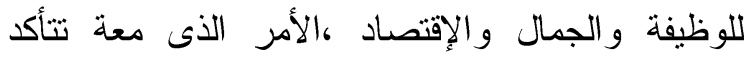

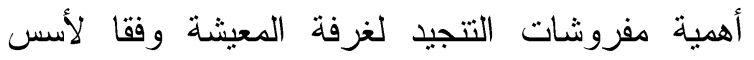
علمية ومعايير محددة، وحدوث تدهور و إتساخ القماش لتشني

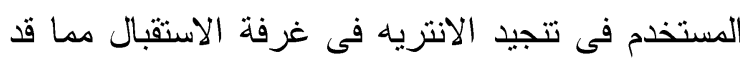

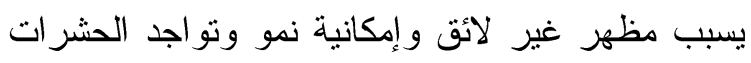

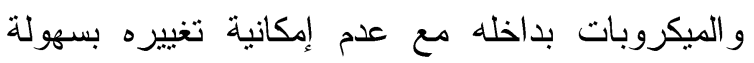

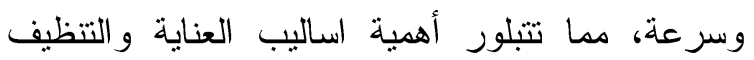
المتبعة مع تلك المفروشات والتى تضمن جودة أدائها

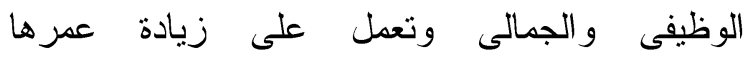

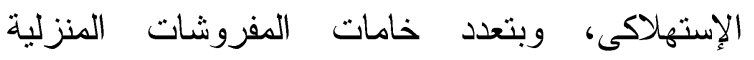
المواكب للتطور التكنولوجى فى الأونة الخيرة ،ولذا فقد

تمثلت مشكلة هذا البحث فى التساؤلات التالية:

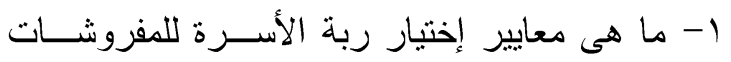

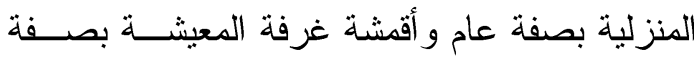

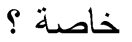

ץ- ما هو تأثثر طرق الإستخدامها للمبحوثات علــى

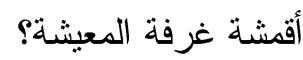

ويجب الاهتمام بإختبار الاثاث وترتيبه فى منطقة

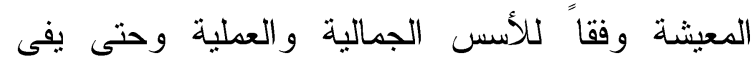
بإحتياجات جميع أفراد الأسرة، ويجب أن تتمتع أقمشة ولثة تتجيد أثاث غرفة المعيشة بجميع ملامح الإسترخاء

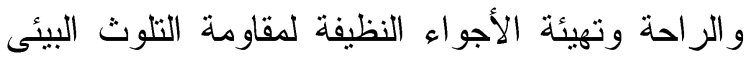
و إنتشار الجر اثيم و الميكروبات (2001- Michael). ونظر الما تبين من أن هناك عدد ضخم من الألباف

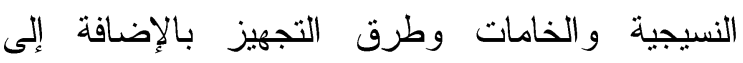

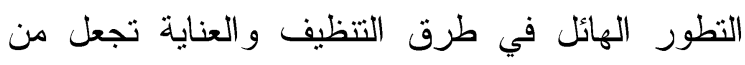
الصعب إختيار الطريقة المناسبة للعنايه بكل نوع من ون هذه المنتجات بالنسبة للمستهلكين ،وكذلك القائمين

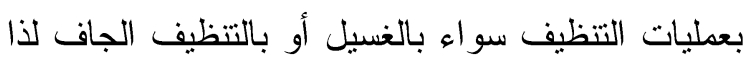
كان لابد من وضع رموز مصورة توضح طرق العنايه

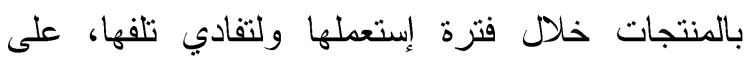
شعير (1991).

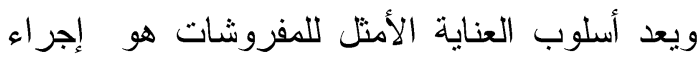

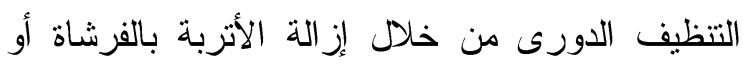
المكنسة الكهربائية والغسيل بإضافة كمية من الكلور و الماء النظيف الذى له تأثير فى عملية التطهير مع باصنه الحرص على تجفيفها فى ضوء الثمس والذى يساعد لهاء على القضاء على نسبة كبيرة من الكائنات الحية الدقيقة و التى تتمل الفطريات المتواجدة بالبيئه الداخلية وعلى لئى

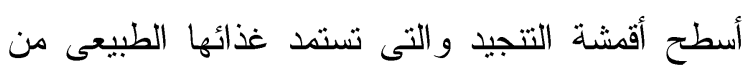
الخامات العضوية الرطبة مثل المفروشات المنزليه، (نجوى حسن وأخرون، 7 . . r).

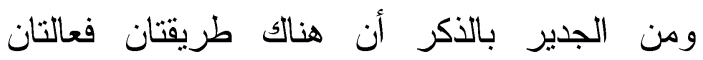
لتنظيف المفروشات، الأولى:هى التنظيف الجاف (دراى كلين) وتستخدم هذه للمفروشات الحساسة الناعمة، و الطريقه الثانيه:هى التى تستخدم البخار حيث أن درجة

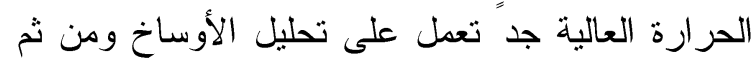

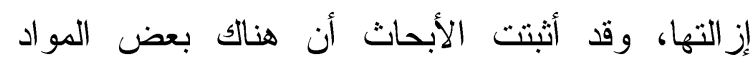
الكيميائية المستخدمة لتظيف أقمشة التتجيد تقتل الكثير من البكتيريا و الفيروسات العالقة بالمفروشات و الاقمشة، .cosmictherap.com, 2020) 
الأقمشة المستخدمة فى تتجيد قطع الأثاث وقد تكون ثابتة أو متحركة.

كما يعرفه (2008, Christophers) هو أى قماش ماش

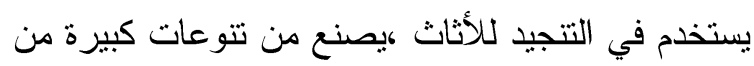

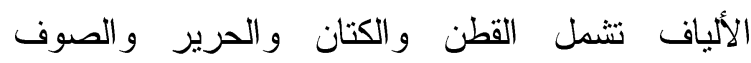

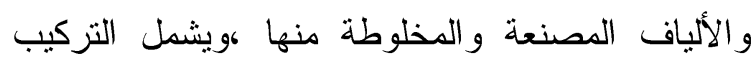

$$
\text { النسجي السادة و المبرد و الأطلس و الجاكارد. }
$$

غرفة المعيشة: Living room

تذكر احلام الطباخ (1997) أن منطقة غرفة

المعيشة هى الفراغ الرئيسى فى الوحدة السكنية ويمثل

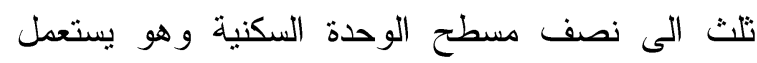
لإستقبال الضيوف و الجلوس وممارسة الهوايات وتتاول الطعام و الأنشطه المختلفة وهو إما فراغ واحد وأو مقسم

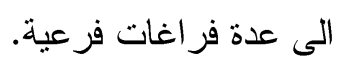

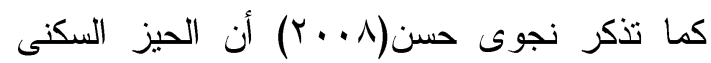

الذى يمارس به العديد من الوظائف، فقد يقوم بدور

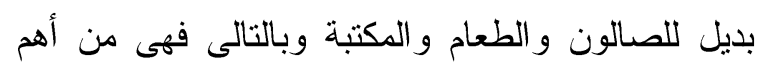

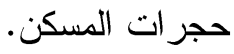
أساليب العناية بالأثاث و المفروشات:

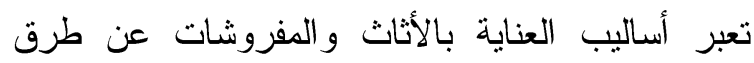
المعالجة و الصيانة المختلفة للخامة سواء كانت ميكانيكية او رطبة او بأستخدام المنظفات الصناعية والتى تهدف لإزلة الأتربة والبقع العالقة مع الحفاظ على رونى رونق الخامة ومظهر ها (Emre \& Nuray , 2010). أجهزة التنظيف بالبخار : يعرف Mark Spelman (2019)) أجهزة التنظيف بالبخار للأثاث المنجد هو جهاز تتظيف

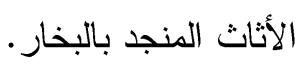

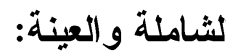

تمنلت شاملة البحث فى جميع السيدات قى مدينة الاسكندرية، وقد نم إجراء هذه الدراسة على عينة

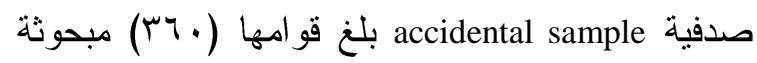
من مجموع السيدات في مدينة الإسكندرية.
ب- ما تأثير عمليات التنظيف و العناية المختلفــة علــى

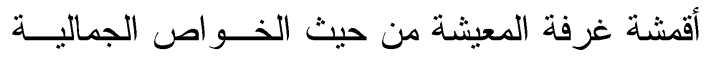
و الوظيفية و الإقتصادية؟

ع- ما هى معارف عينة الدراسة تجاه الأجززة الحديثــة المستخدمة فى تتظيف قماش تتجيد غرفة المعيشة؟ عاره

\section{أهداف البحث}

أستهدف البحث بصفة رئيسية دراسة ممارسات

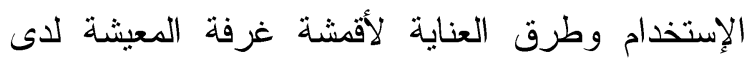
عينة من السيدات بمدينة الإسكندرية ومعارفه بالأجهزة الحديثة لتتظيف هذه الاقشة، وذلك من خلال الأهداف

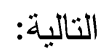

ا ـ در اســـة الخصــــائص الإجتماعيــة و الإقتصــــادية للمبحوثات عينة البحث.

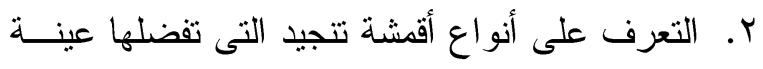
البحث بغرفة المعيشة. r. دراسة ممارسات عينة البحث لطــرق الإســـتخدام المختلفة بأقمشة تتجيد غرفة المعيشة.

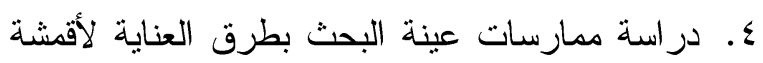
تتجيد غرفة المعيشة. ○. التعرف على معارف عينة بحث عن أجهزة تنظيف قماش تتجيد غرفة المعيشة. 7 ا. دراسة علاقة المتغيرات المستقلة بالمتغيرات التابعة

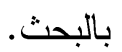

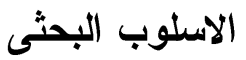

منهج الارسة: اتبع في هذا البحث المنهج الوصفي

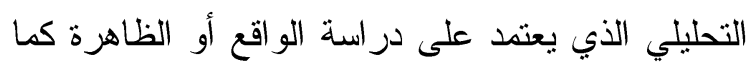
توجد في الواقع ويهتم بوصفها وصفاً دقيقاً ويعبر عنها

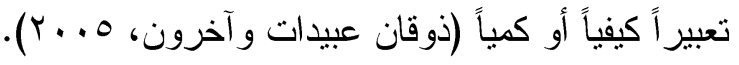
التعاريف البحثية والإجرائية:

قماث التتجيد: Upholstery Fabrics

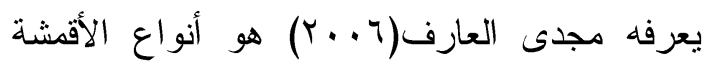

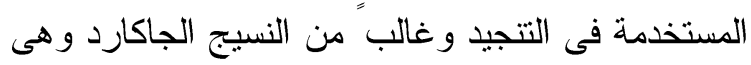


T. لا يوجد علاقة إرتباطية بين الخصائص

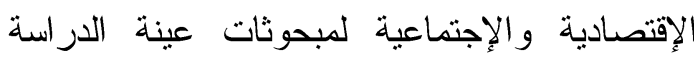

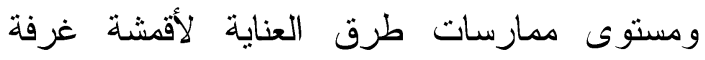

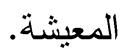
V. لا يوجد علاقة إرتباطية بين الخصائص

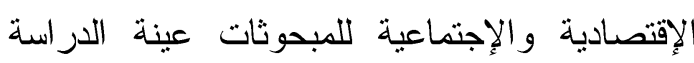
ومستوى إجمالى الممارسات (الاستخدام وطرق العناية) لأقششة غرفة المعيشة.

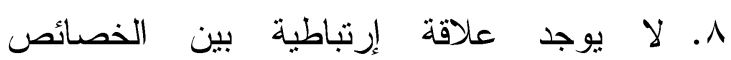
الإقتصادية والإجتماعية للمبحوثات عينة الدراسة لإنة ومعارف المبحوثات تجاه أجهزة التنظيف لأقمشة

غرفة المعيشة. إسلوب تجميع ومعالجة البيانات:

تم استخدام استمارة أستبيان وجمعها بالمقابلة الثخصية لعينة الدراسة وقد اشتملت هذه الاستمارة

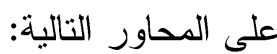
المحور الأول: يتعلق بالبيانات الاجتماعية والاقتصادية الخاصة بعينة الدراسة، حيث اثتملت على السن للمبحوثات، والحالة الاجتماعية للمبحوثات و المستوى لينائ التعليمى لهن، وعمل المبحوثات، و المستوى التعليمى

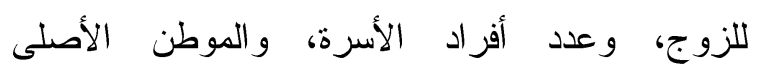
،ومتوسط الدخل الثهرى للأسرة. تحويل البيانات الوصفية إلى كمية: تم تمييز فئات كل

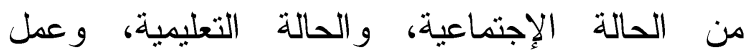
المبحوثات و العمر ، والحالة التعليمية للزوج، و الموطن

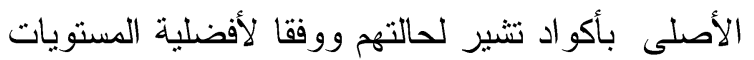
المختلفة لكل منهم كلما أمكن، فى حين نم حساب المتوسط الحسابى والإنحر اف المعيارى لكل من عدد أفراد الأسرة، ومتوسط الدخل الأسرى وبناء علية تم نصنيف كل منهم إلى ثلاثة فئات.

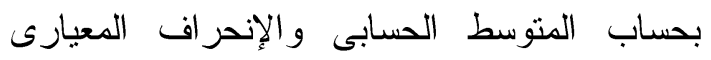

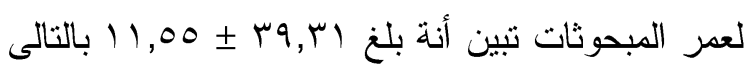

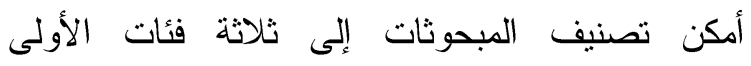

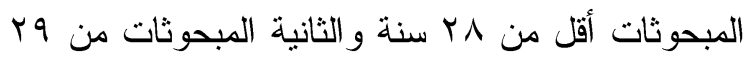

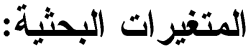

لتحقيق أهداف البحث تم تصنيف المتغيرات البحثية فى مجموعنين على النحو التالى: المتغيرات المستقلة: و هى بعض الخصائص الإجتماعية والإقتصادية لعينة الدراسة وقد أثنتملت على السن، و الحالة الإجتماعية للمبحوثات و المستوى التعليمى لهن، وعمل المبحوثات، وعمل الزوج ،و المستوى التعليمى للزوج ،وعدد أفراد

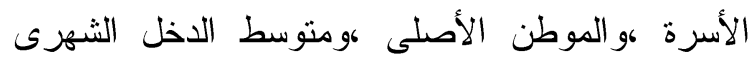

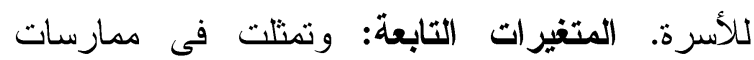
المبحوثات عينة الدراسة نحو إستخدام أقششة تتجيد

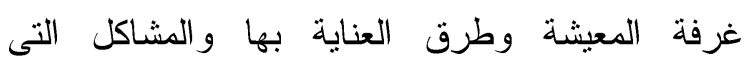
تو اجهها المبحوثات لأقشة تتجيد غرفة المعيشة.

\section{الفرض البحثي}

تمت صياغة الفروض البجثية فى صورتها الصفرية كما يلى: 1. لا يوجد علاقة إقتران بين الخصائص الإقتصادية

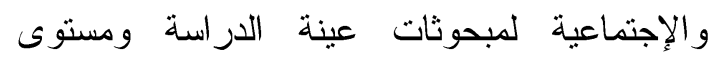
ممارسات الاستخدام لأقششة غرفة المعيشة.

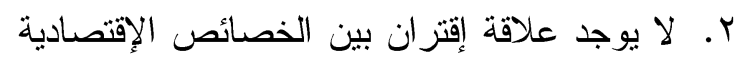

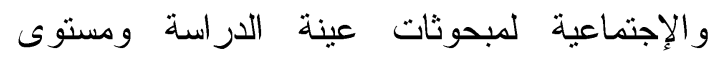
ممارسات طرق العناية لأقمشة غرفة المعيشة. r. لا يوجد علاقة إقتران بين الخصائص الإقتصادية

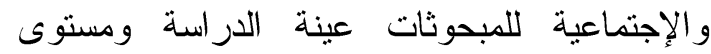

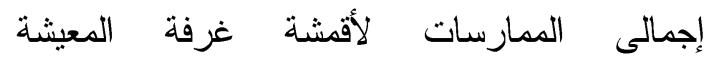
(الإستخدام وطرق العناية).

ـ. لا يوجد علاقة إقتران بين الخصائص الإقتصادية

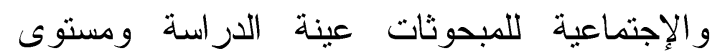
معارف المبحوثات تجاه أجهزة التتظيف لأقشة غرفة المعيشة. ه. لا يوجد علاقة إرتباطية بين الخصائص الخدية الإقتصادية والإجتماعية للبحوثات عبنة الدراسة

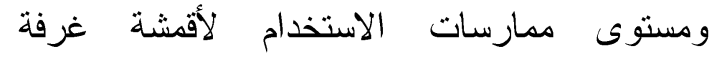

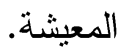


1. معارف المبحوثات تجاه إجمالى الممارسات للاستخدام وطرق العناية لأقشة غرفة الهمات المعيشة،

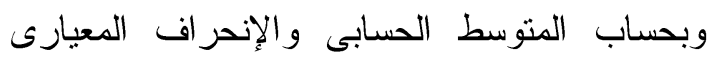
لمستوى تقييم المبحوثات من حيث إجمالى لئى الممارسات نحو الاستخدام وطرق العناية لأقمشة لهن

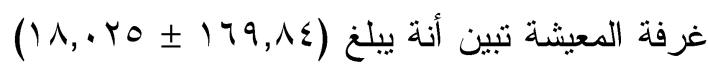
حيث بلغ حدود المستوى المنخفص(أقل من الهن

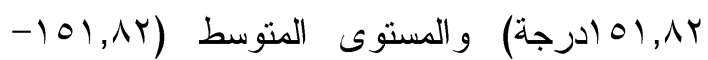

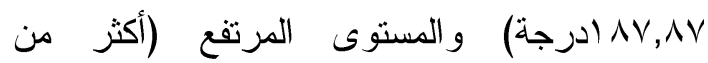
( ) ا درجة).

r. معارف المبحوثات تجاه أجهزة التنظف لأقمشة غرفة المعيشة أثنتمل على 1 اسؤال متعلقة بمعارف لهُه المبحوثات بطرق العناية لأقمشة التتجيد بأجهزة

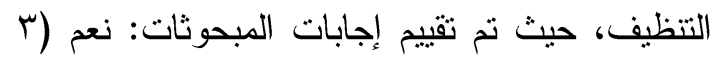
درجات)، لا أعرف (درجتان)، لا (درجة واحدة). وبحساب المتوسط الحسابى والإنحراف المعيارى للارجة الدالة على معارف المبحوثات لأجهزة العناية

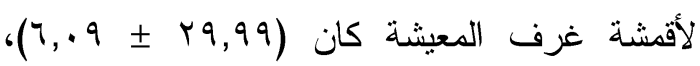
وبناء على ذلك تم تقييم مستوى معارف المبحوثات لأجهزة العناية لأقشة غرف المعيشة الى ثلاث فئات

$$
\text { صدق صرتفع ومتوسط ومنخفض. }
$$

نم التأكد من صدق الاستبيان عن طريق الصدق البات البنائى و المبنى على معامل الارتباط بين درجات كل هل هلئ محور من محاور الاستبيان والدرجة الكلية للاستبيان ويتضح من جدول (1) وجود علاقة ارتباطية موجبة عند مستوى احتمالية (1., (•) بين مختلف محاور الاستبيان والدرجة الكلية له مما يدل على صدق أداة

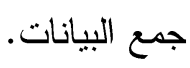
r- بات أداة جمع البيانات

تم إجراء إختبار الثبات بإستخدام معامل ألفات

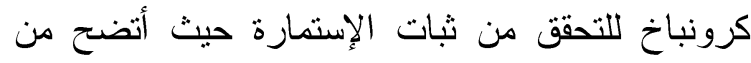

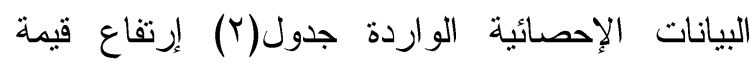

إلى •0 سنة والثالثة أكثر من إه سنة، وبحساب

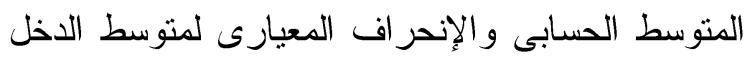

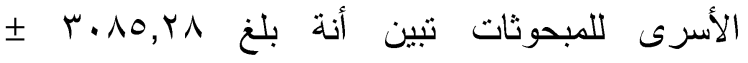
r •, 1709 بالتالى أمكن تصنبف المبحوثات إلى ثلاثة فئات الأولى المبحوثات اللاتى بلغ متوسط دخلهن

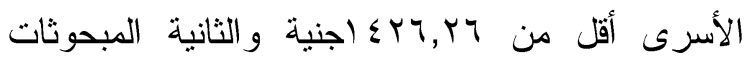

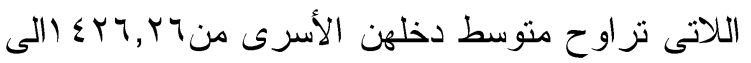

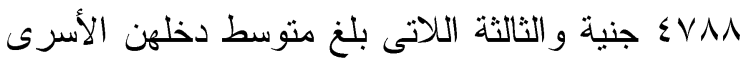

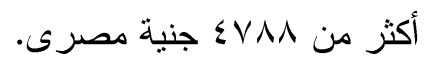
اسلوب تقنين أداة جمع البيانات

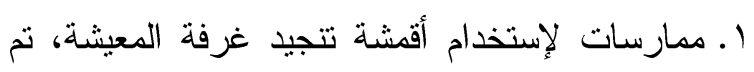

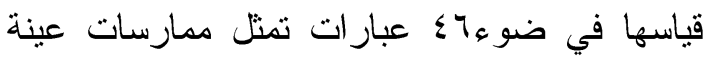

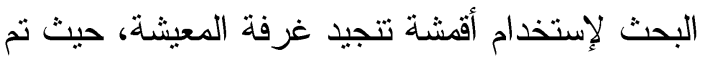

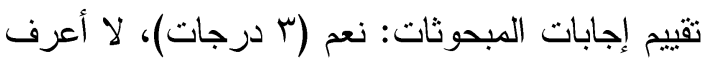
(درجتان)، لا (درجة واحدة). وقد نم تقسيم مستوى

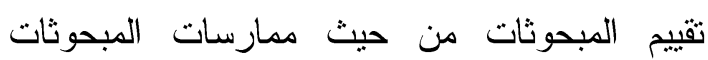
لاستخدام غرفة المعيشة، إلى ثلاث فئات في ضوء

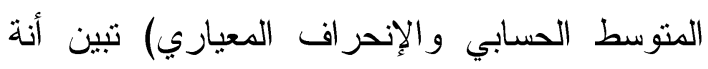

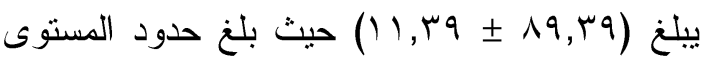

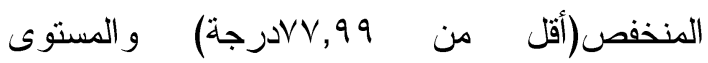

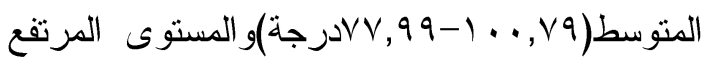

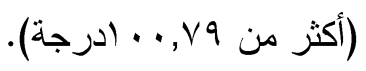

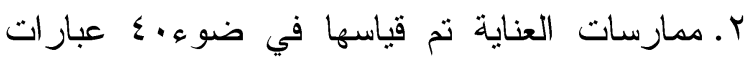
تمنل ممارسات عينة البحث لإستخدام أقشة تنجيد

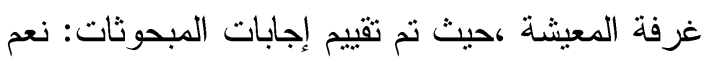
(ץ درجات)، لا أعرف (درجنان)، لا ل (درجة و احدة). وقد تم تقسيم مستوى ممارسات المبحوثات لطرق العناية المختلفة لأقمشة غرف المعيشة، إلى مصلى ثلاث فئات في ضوء المتوسط الحسابى والانحر اف

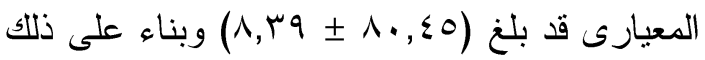
تم تقييم مستوى معارف المبحوثات نحو ممارسات

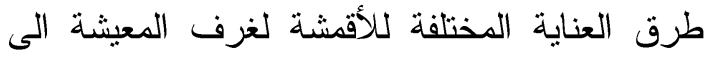
ثلاث فئات مرتفع ومتوسط ومنخفض. 
تم دراسة الخصائص الاجتماعية و الاقتصادية للمبحوثين و المتمثلة في السن، و الحالة الاجنماعية،

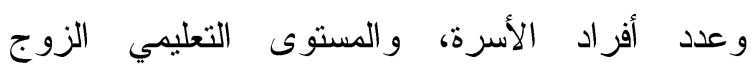
و الزوجة، ومهنة الزوجة، ومتوسط الدخل الثهري

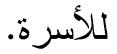

أظهرت النتائج فى جدول (r) أن أكثر من نصف

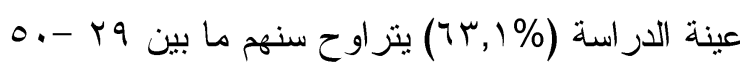

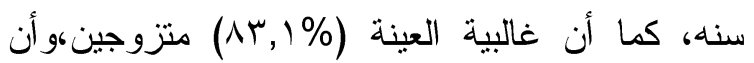

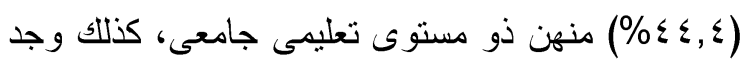
أن أكثر من نصف العينة (0^,9\%) تعملن ويتراوح

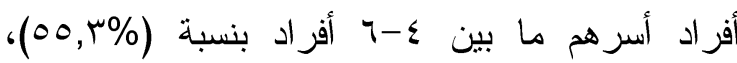

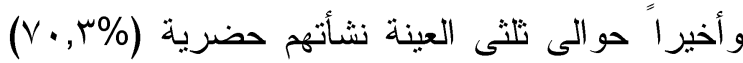

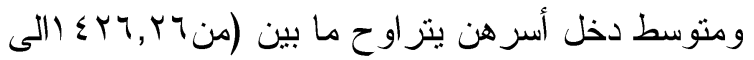

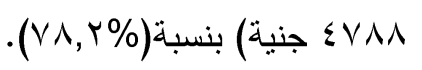

( النتائج المتعلقة بممارسات إستخدام أقمشة تنجيد (V) غرفة المعيشة:

تفضيل أنواع الاقششة تنجيد غرقة المعيشة: يوضح جدول(§) ألوان و أقمشة تتجيد غرفة المعيشة

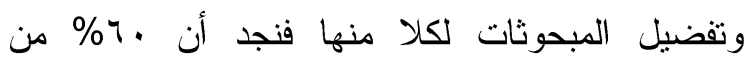

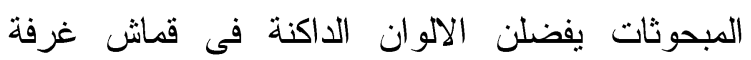

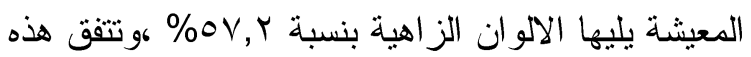

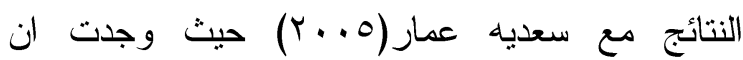
المبحوثات كان يفضلن استخدام الالوان الداكنه للاقمشه المستخدمه فى كل من غرفتى تتاول الطعام و المعيشه.

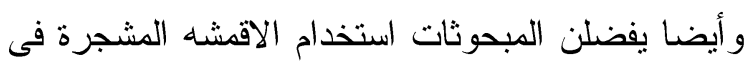

الخداديات الخاصده بغرفة المعيشه.
معامل ألفا مما يدل على إتساق وثبات الإستبيان حين

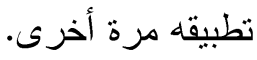
أسلوب تحليل البيانات البحثية:

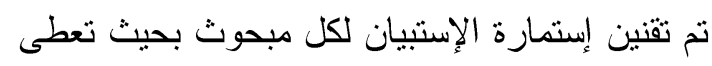

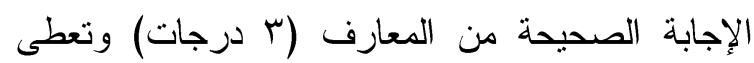
الإجابة بلا أعرف (درجتان) وتعطى الإجابات الخاطئة (درجة واحدة)، ثم جمع درجات كل محور بكل إستمارة

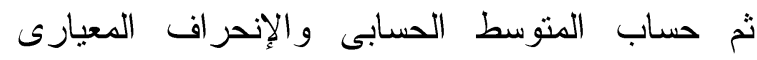
بإستخدام الكمبيوتز وتم تقسيم المعارف الى مستوى متوسط وهو ما يقع بين (المتوسط ـ الإنحراف

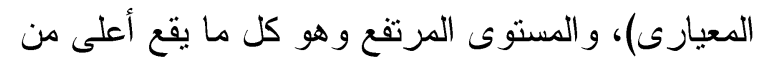

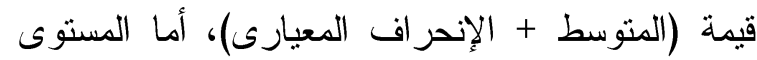

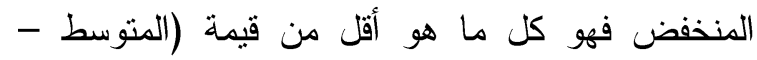
الإنحر اف المعيارى). المعاملات الإحصائية تم إستخدام النسب المئوية لعرض نتائج الدراسة الميدانية كما تم إستخدام إختبار مربع كاى، ومعامل الإرتباط البسيط لإيجاد العلاقات بين المتغيرات المستقلة و المتغيرات التابعة، وذللك من خلال إستخدام برنامج

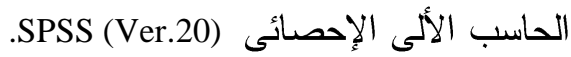

$$
\text { النتائج البحثية و المناقشة }
$$

أولا: نتائج الاراسة الميدانية

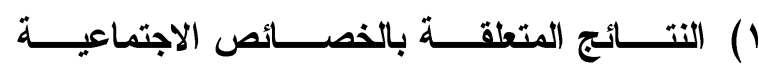
و الاقتصادية للمبحوثات موضع الار اسة:

\begin{tabular}{|c|c|c|c|}
\hline معامل الإرتباط & عدد العبارات & محاور الإستبيان & \\
\hline$* *, \wedge 91$ & $\varepsilon 7$ & ممارسات الإستخدام & 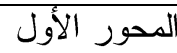 \\
\hline$* *, \lambda r y$ & $\varepsilon$. & ممارسات العناية & المحور الثانى \\
\hline$* *, \varepsilon \mu_{q}$ & 17 & معارف المبحوثات تجاه أجززة العناية لأقمشة غرفة المعيشة & المحور الثالث \\
\hline
\end{tabular}

جدول ا: قيم معامل الإرتباط للالالة على صدق محاور أداة جمع البيانات 
جدول r: قيم معامل ألفا كرونباخ للالالة على ثبات محاور أداة جمع البيانات

\begin{tabular}{|c|c|c|c|}
\hline معامل ألفا كرونبخ & عدد العبارات & محاور الإستبيان & \\
\hline$\cdot, 70 \leqslant$ & $\leqslant 7$ & ممارسات الإستخدام & المحور الأول \\
\hline$\cdot, \pi 74$ & $\varepsilon$. & ممارسات العناية & المحور الثانى \\
\hline$\cdot, \wedge \vee \mu$ & 17 & جهزة العناية لأقمشة غرفة المعيشة & المحور الثالث \\
\hline
\end{tabular}

جدول r: توزيع المبحوثين وفقاً للخصائص الاجتماعية والاقتصادية

\begin{tabular}{|c|c|c|c|c|c|}
\hline$\%$ & (ن) (لعدّد) & والاقتصـــــــائص الاجتماعية ـــــة & $\%$ & (ن) (لعدد) & والاقتصــــــادية ائص الاجتماعيـــــــة \\
\hline & & 0- المستوى التعليمى للزوج & & & 1 - 1- السن \\
\hline$r, q$ & $1 \leqslant$ & أمى & $I V, 0$ & $4 \pi$ & أقل من Y T سنة \\
\hline 14,0 & $\leqslant \wedge$ & يقر أ ويكتب & 74,1 & KYV & منو ب الى •0 سنة \\
\hline ry & IYA & مؤهل منوسط & 19,8 & $V \cdot$ & اه سنة فأكثر \\
\hline$\varepsilon 1, r$ & $1 \leqslant V$ & جامعى & & & Y- الحالة الاجتماعية للمبحوثات \\
\hline \multirow[t]{2}{*}{$0, r$} & 19 & فوق جامعي & $Y, Y$ & $\Lambda$ & أعزب \\
\hline & & 1- حجم الأسمرة & $\Delta r, 1$ & $r 99$ & متزوج \\
\hline $0, r$ & 19 & أقل من Y- r أفر اد & $\varepsilon, r$ & 10 & مطلق \\
\hline $00, r$ & 199 & ع- بأفر اد & $1 \cdot, 7$ & rᄉ & أرمل \\
\hline \multirow[t]{2}{*}{$r q, \varepsilon$} & $1 \leqslant Y$ & أكثر من 7 أفر اد & & & r- المستوى التعليمية للمبحوثات \\
\hline & & V - النشُأة الاصلية & $\Lambda, 7$ & r & أمى \\
\hline$r q, V$ & $1 \cdot V$ & ريف & 10,7 & 07 & يقر أ ويكتب \\
\hline \multirow[t]{3}{*}{$V \cdot r$} & ror & حضر & $r r, q$ & $\Lambda 7$ & مؤ هل متوسط \\
\hline & & & $\varepsilon \varepsilon, \varepsilon$ & 17. & جامعي \\
\hline & & 1- متوسط دخل الأسرة & $v, 0$ & TV & فوق جامعي \\
\hline$v, r$ & YY & أقل من ד, צד ا (جنية مصرى & & & ع - مهنة المبحوثات \\
\hline$V \wedge, Y$ & $T V V$ & 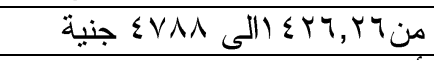 & $0 \wedge, 9$ & YIT & تعمل \\
\hline $1 \leqslant, \varepsilon$ & 01 & 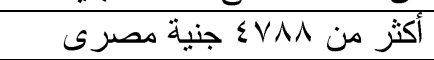 & $\S 1,1$ & $1 \leqslant 1$ & لا تعمل \\
\hline
\end{tabular}

جدول تكرار ؛ : تفضيل المبحوثات تجاه أنواع أقششة تتجيد غرفة المعيثة

\begin{tabular}{|c|c|c|c|c|c|}
\hline$\%$ & $\gamma$ & $\%$ & نعم & بنود الاستبيان & p \\
\hline$\varepsilon$. & $1 \leqslant \varepsilon$ & 7. & rIT & أفضل الالوان الداكنة فى قماش الانتريه & 1 \\
\hline$\varepsilon r, \Lambda$ & $10 \leqslant$ & $O V, Y$ & $r \cdot T$ & أفضل الالوان الز اهية فى قماش الانتريه & $r$ \\
\hline$\Lambda V, r$ & TIE & $I Y, \Lambda$ & $\leqslant 7$ & الانتزيه ذو قماش جلد & $r$ \\
\hline$\pi r, 0$ & TrO & $r v, 0$ & $1 \% 0$ & الانتريه ذو قماش قطيفة & $\varepsilon$ \\
\hline$V 0,0$ & TVY & $r \leqslant, \varepsilon$ & $\Lambda \Lambda$ & الانتريه ذو قماش شمواه & 0 \\
\hline $4 r, 9$ & rr. & Mq, & $1 \%$. & الانتريه ذو قماش قطنى & 7 \\
\hline
\end{tabular}

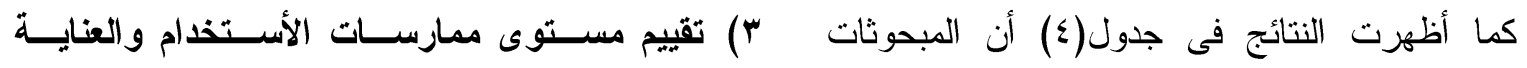
ومعارف أجهزة التتظيف لنتائج الاراسة الميدارئية يفضلن أن يكون قماش تتجيد غرفة المعيشة قماش للأقمشة تنجيد غرفة المعيثة: ا. تقييم مستوى الممارسات المبحوثـات لأســتخدام قطيفة بنسبة \%rv,0 يليها القماش القطنى بنسبة

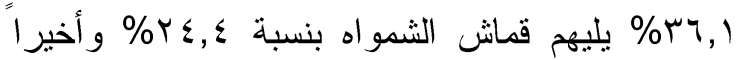
غرف المعيثة: عند دراسة مستوى ممارسات الإستخدام لغرفة المعيشة أضحت النتائج بجدول(0) أن مستوى ممارسات جاء تفضيل القماش الجلد فى المرتبة الاخيرة بنسبة

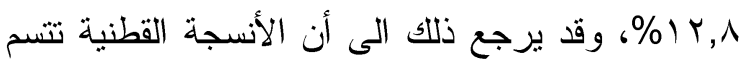
بالدفء والمظهر الفاخر وهذا يتفق مع ما ذكرنه دعاء

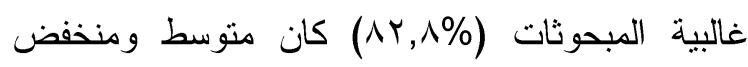


r. تقييم المستوى الإجمالى الممارسات للمبحوثات لإستخدام و العناية بأقمشة غرف المعيشة:

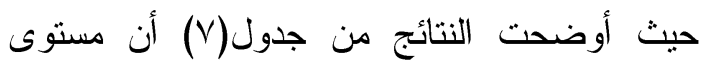
ممارسات غالبية المبحوثات (10,^\%) كان منوسط

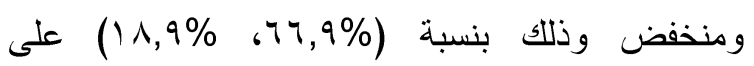
التوالى. وركذ بتضح إنخفاض ممارسات المبحوثات بشأن إجمالى الممارسات لأقمشة غرف المعيشة، ويتفق

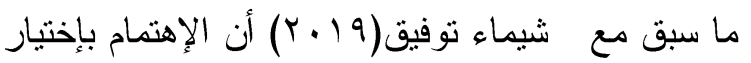
وإستخدام مكملات الأثاث بحيث تكون سهلة العناية و الصيانة لتوفير الوقت و الجهد و الميز انية للأسرة. ؛. تقييم مستوى معارف المبحوثات لأجهزة العناية لأقمشة غرف المعيشة:

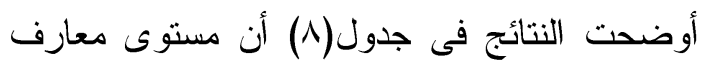
المبحوثات لأجهزة العناية لأقمشة غرف فرل المعيشة

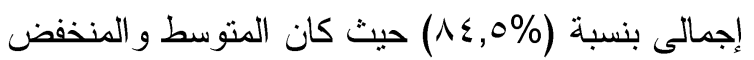

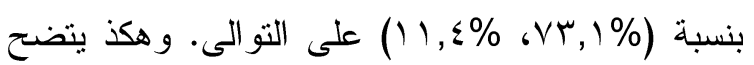

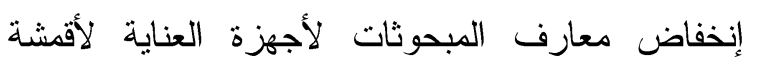
غرف المعيشة. تستتتج الباحثة انخفاض معارف المبحوثات نحو أجهزة العناية لأقمشة غرف المعنيشة المغنة إلى العديد من الإختيارات أمام المبحوثات مثل إمكانية تجديد القماش أو غسله أو استخدام كسوة خرجية قابلة

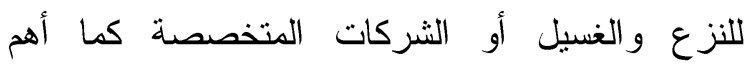
الأسباب أن العنية بالأقشنة يتم على فتر ات متباعدة.

جدول ه: يوضح المتوسط الحسابى والآحر اف المعيارى والنسبة المئوية لمستوى الممارسات الاستخدام لغرفــة المعيشة

\begin{tabular}{|c|c|c|}
\hline$\%$ & العدد (ن = ، צ r) & ممارسات الاستخدام (qq, \\
\hline $19, Y$ & 79 & منخفض(أقل من 9 مV, 9 درجة) \\
\hline $7 r, 7$ & rrq & 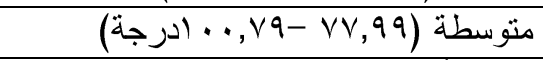 \\
\hline$I V, Y$ & Tr & مرتفع(أكثر من v9, • . ادرجة) \\
\hline
\end{tabular}

جدول جا: يوضتح المتوسط الحسابى والاتحر اف المعيارى والنسبة المئوية لمستوى الممارسات العنايــة بغرفــة المغيثة

\begin{tabular}{|c|c|c|}
\hline$\%$ & 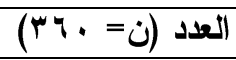 & 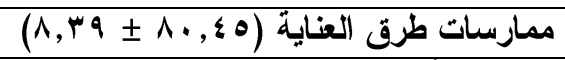 \\
\hline YI, 乞 & VV & منخفضة(أقل من O., 0 (Vادرجة) \\
\hline $7 Y, Y$ & TYE & 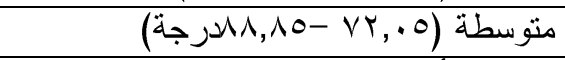 \\
\hline 17,2 & 09 & 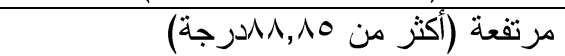 \\
\hline
\end{tabular}

وذلك بنسبة (\% 7, 77، \% ب, 1 ) على التو الى. وهكذ يتضح إنخفاض ممارسات المبحوثات بشأن استخدام

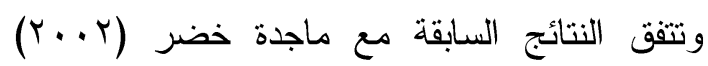

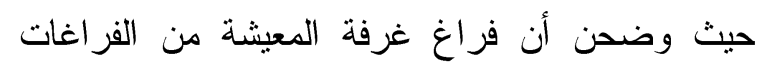

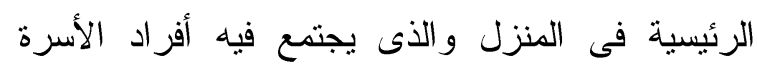

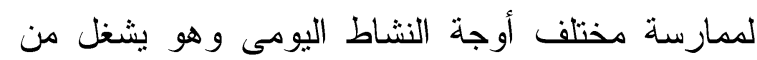

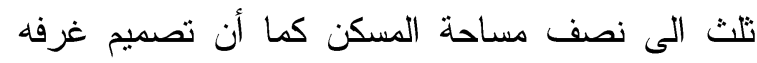

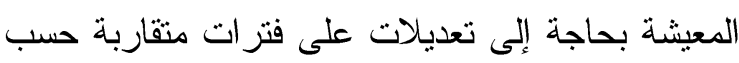
r. تقييم مستوى الممارسات المبحوثات لطرق العناية عند دراسة مستوى ممارسات العناية بغرفة المعيشة أوضحت النتائج بجدول (7) أن مستوى ممارسات

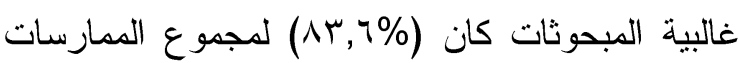

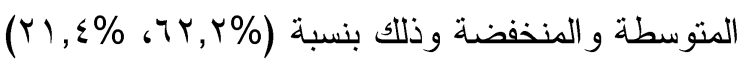

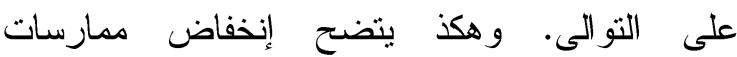
المبحوثات بشأن طرق العناية لأقمشة غرف المعيشة، و هذا يتقق مع ما ذكرته و لاء مصطفى (T . . Y). 
جدول V: يوضح توزيع المبحوثات وفقا لمستوى إجمالى الممارسات لأقمشة غرفة المعيشة

\begin{tabular}{|c|c|c|}
\hline$\%$ & 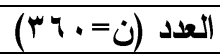 & 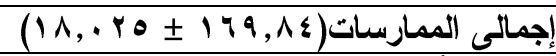 \\
\hline 11,9 & 40 & متوسطة (أقل من بر, اه ادرجة) \\
\hline 77,9 & $r \leqslant 1$ & 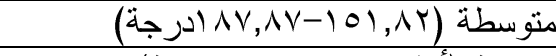 \\
\hline $1 \varepsilon, Y$ & 01 & مرتفعة (أكثر من AV,AV ادرجة) \\
\hline
\end{tabular}

جدول ^: يوضح توزيع المبحوثات وفقا لمستوى المعارف الاجهزة العنايةلأقمشة غرفة المعيشة

\begin{tabular}{|c|c|c|}
\hline$\%$ & العلد (ن=.. צ"r) & 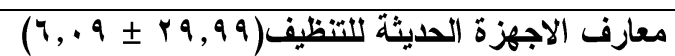 \\
\hline $11, \varepsilon$ & $\varepsilon 1$ & منخفضة (أقل من 9 مي, ז זدرجة) \\
\hline$\overline{v r, 1}$ & rTY & 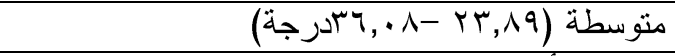 \\
\hline 10,4 & 07 & مرتفعة (أكثر من ^ .، ب؟ז درجة) \\
\hline
\end{tabular}

وأوضح الجدول عدم وجود علاقة إقتران معنوية

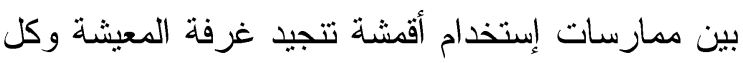

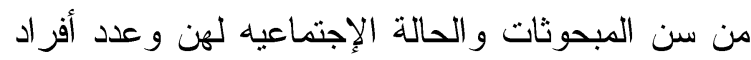

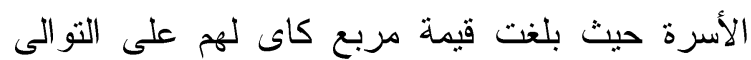
$. \wedge, 99, r Y, T \Lambda, Y, T r$ بالتالى ومن خلال إستعراض النتائج يمكن رفض الفرض البحثى جزئيا وقبولة جزئيا. لللتحقق من صحة الفرض البحثى الثنانى و الذى ينص النص

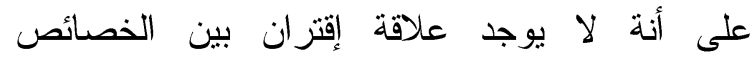

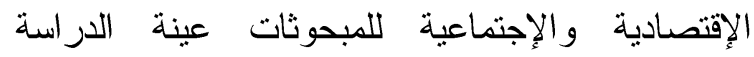
وممارسات طرق العناية لأقشة تنجيد غرفة المعيشة، الإنة تم حساب قيم مربع كاى بين المتغيرات البحثية المنصوص عليها بالفرض حيث أنضح من الننائج الإحصائية الواردة بجدول (9) وجود علاقة إقتران

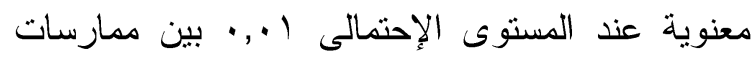
طرق العناية لأقشة تنجيد غرفة المعيشة وكل من الإندان الحالة الإجتماعية للمبحوثات و المستوى التعليمى لهن

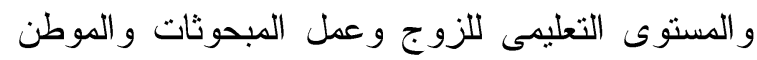

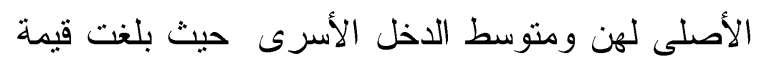

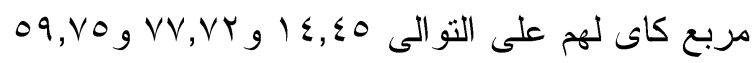

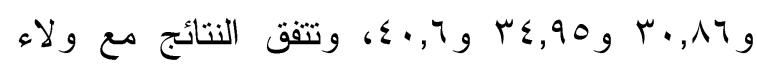

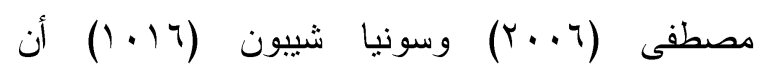
ممارسات العناية بالمفروشات ينأثر بكلا من الحالة الإجتماعية للمبحوثات والموطن الأصلى لهن وعملهن

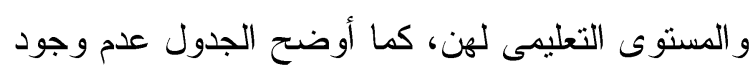

وقد أكداكب من (Yiin, 2002) الى أهمية استخدام أجهزة العناية حيث إنها تسبب إنخفاض التلوث لأقشه التنجيد

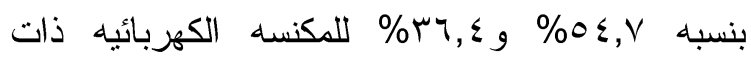
المرشح للهواء و الكفائة العالية و العادية على التو الى. لئه ثانيا: النتائج المتصلة بالعلاقات الإحصائية بين العتغير ات البحثية: 1) العلاقة بين المتغيرات المستقلة والمتغيرات التابعة:

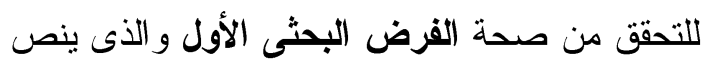
على أن لا يوجد علاقة إقتران بين الخصائص الإن الإقتصادية والإجتماعية للمبحوثات عينة الدراسة لإنة وممارسات إستخدام أقمشة تنجيد غرفة المعيشة، نم الإعنات حساب قيم مربع كاى بين المتغيرات البحثية المنصوص المئي عليها بالفرض حيث دأنضح من النتائج الإحصائية

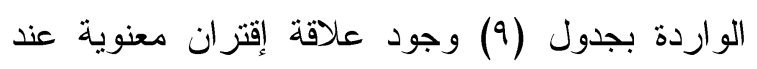

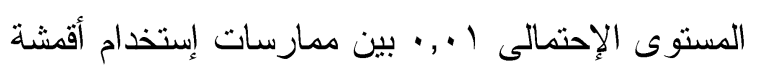
تنجيد غرفة المعيشة وكلا من المستوى التعليمى لهن لهن و المستوى التعليمى للزوج وعمل المبحوثات و الموطن

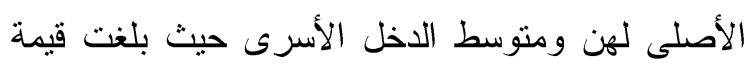
مربع كاى لهم على التو الى ونى

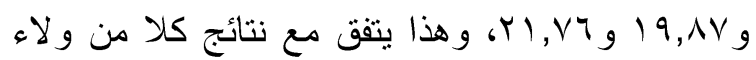

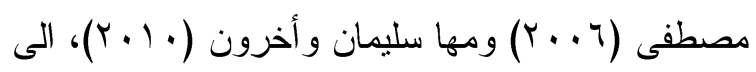
أن ممارسات المبحوثات نحو إستخدام أقشمة تنجيد غرفة المعيشة تتأثر بالمستوى التعليمى للمبحوثات وعملهن ومستوى التعليم للزوج ،مما يدل على دور التعليم فى زيادة وعى الفرد. 
كما أوضح الجدول عدم وجود علاقة إقتران معنوية بين إجمالى الممارسات (الاستخدام وطرق العناية)لأقمشة تتجيد غرفة المعيشة وسن المبحوثات حيث بلغت قيمة مربع كاى لها r • ب. r. بالتالى ومن خلال إستعر اض النتائج يمكن رفض الفرض البحثى جزئيا وقبولة جزئيا.

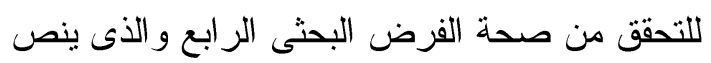

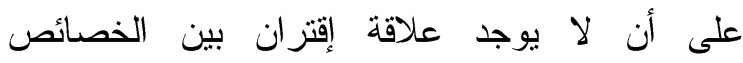

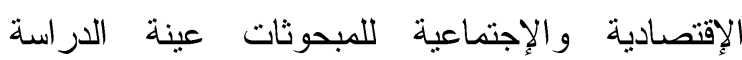
ومعارفهن لأجهزة العناية لأقمشة غرف المعيشة، تماتهابه

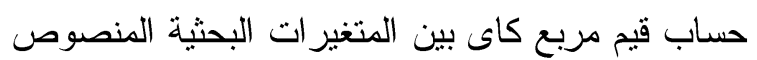
عليها بالفرض حيث أتضح من النتائج الإحصائية

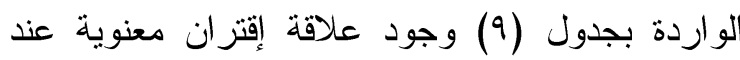

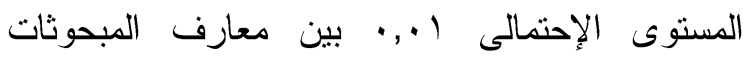

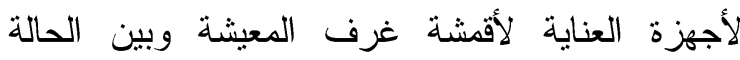
الإجتماعية للمبحوثات حيث بلغت قيمة مربع كاى لها لهابه Y Y, I ا ،ويتفق مع كلا من فاتن لطفى (1990 ) و عبير

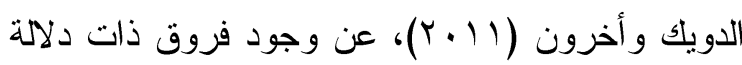
إحصائية في إستخدام ربات الأسر لبعض الأجهزة

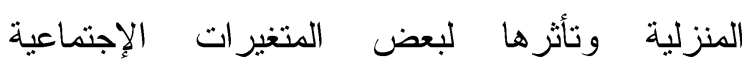
و الإقتصادية للأسرة. كما أتضح من الجدول عدم وجود علاقة إقتران

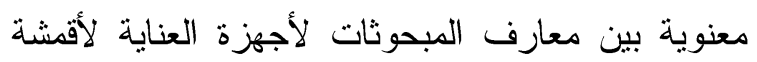

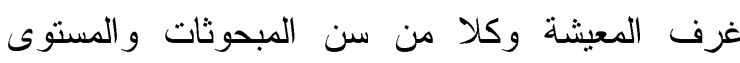

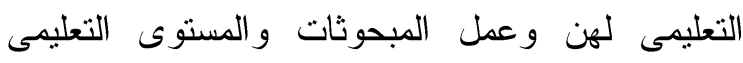
للزوج و عدد أفر اد الأسرة و النشأة الأصلية لهن ومتوسط ولئي

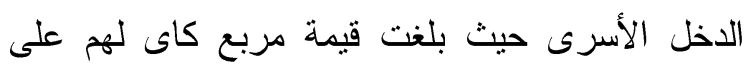

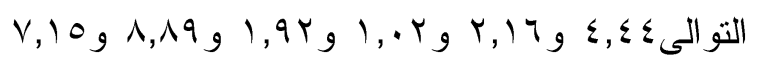
و و.,r, و, r,00. بالتالى ومن خلال إستعر اض النتائج يمكن رفض الفرض البحثى جزئيا وقبولة جزئيا.
علاقة إقتران معنوية بين ممارسات طرق العناية

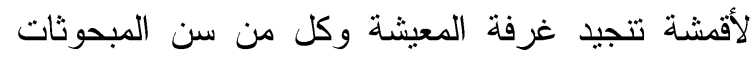

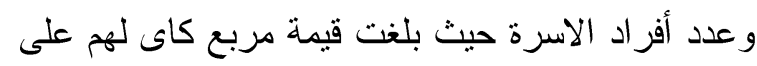

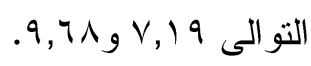
بالتالى ومن خلال إستعر اض النتائج يمكن رفض الفرض البحثى جزئيا وقبولة جزئيا.

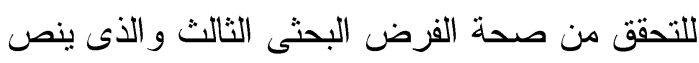
على أن لا يوجد علاقة إقتران بين الخصائص

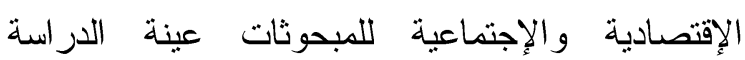
و إجمالى الممارسات (الإستخدام وطرق العناية) لأقمشة تتجيد غرفة المعيشة، نم حساب قيم مربع كاى بين المتغيرات البحثية المنصوص عليها بالفرض هيث هيث أتضح من النتائج الإحصائية الواردة بجدول (9) وجود البئه

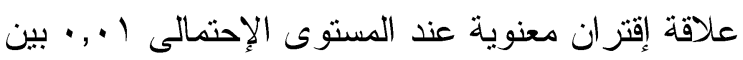
و إجمالى الممارسات (الإستخدام وطرق العناية)لأقمشة تتجيد غرفة المعيشة وكل من الحالة الإجتماعية

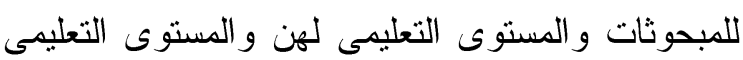
للزوج و عمل المبحوثات و النشأة الأصلية لهن ومتوسط ولئي

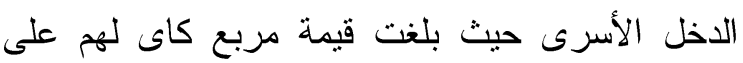

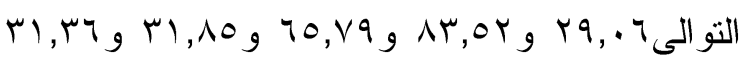

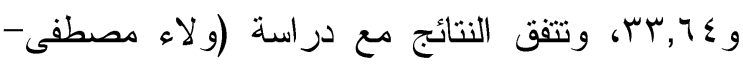

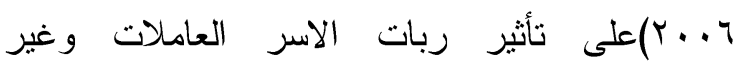
العاملات فى الممارسات الخاصة بالإستخدام و العناية بالمفروشات لصالح السيدات العاملات، وكما أظهرت الدراسة وجود تأثير إحصائى للمستويات التعليمية الأعلى لربات الاسر والممارسات الخاصة الإستخدام و العناية بالمفروشات المنزلية.

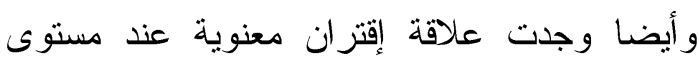
احتمالى 0 ., · بين وإجمالى الممارسات (الاستخدام وطرق العناية)لأقمشة تتجيد غرفة المعيشة وبين عدد والهات

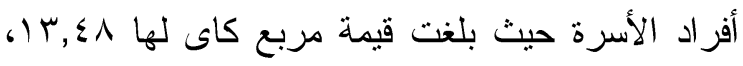


جدول 9: يوضح قيم مربع كاى بين المتغيرات المستقلة والمتغيرات التابعة

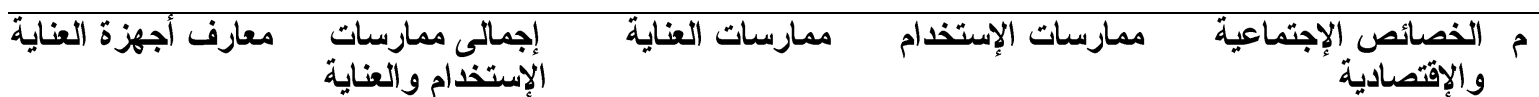

\begin{tabular}{|c|c|c|c|c|c|c|}
\hline$(\varepsilon)$ & $\varepsilon, \varepsilon \varepsilon$ & $(\varepsilon) \quad \varepsilon, \Gamma$ & $(\varepsilon) \quad v, 19$ & $(\varepsilon) \quad V, \pi r$ & السن & 1 \\
\hline$* *(\urcorner)$ & $I \varepsilon, Y Y$ & $* *(7) ~ \curlyvee 9, .7$ & $* *(T) 1 \leqslant, \leqslant 0$ & (T) $Y Y, T A$ & الحالة الإجتماعية & r \\
\hline$(\wedge)$ & Y,1T & $* *(\wedge) \wedge r, O r$ & $* *(\wedge) \vee V, V Y$ & $* *(\wedge) \quad T V, 0$ & المستوى التعليمى & $r$ \\
\hline$(Y)$ & $1, \cdot r$ & $* *(r) \Gamma 1, \wedge 0$ & $* *(r) \Gamma \cdot, \wedge \uparrow$ & $* *(r) \Upsilon q, \wedge \vee$ & عمل المبحوثات & $\varepsilon$ \\
\hline$(1 \cdot)$ & $\wedge, \wedge 9$ & $* *(1 \cdot) 70, \vee 9$ & $* *(1 \cdot) \circ 9, \vee 0$ & $* *(1 \cdot) \leq q, r)$ & المستوى التعليمى للزوج & 0 \\
\hline (T) & $V, 10$ & $*(7) \backslash \Psi, \leqslant \wedge$ & (7) 9,71 & (7) 1,99 & عدد أفر اد الاسرة & 7 \\
\hline$(r)$ & $r, r_{0}$ & $* *(\Upsilon) \Gamma, T$ & $* *(r) \Gamma \varepsilon, 9 Y$ & $* *(\Upsilon) 19, \wedge V$ & الموطن الأصلى & $\checkmark$ \\
\hline$(\varepsilon)$ & $r, 00$ & $* *(\xi) r T, Y \varepsilon$ & $* *(\xi) \quad \varepsilon \cdot, \uparrow$ & $* *(\xi) Y \backslash, V \uparrow$ & مستوى دخل الأسرة & $\wedge$ \\
\hline
\end{tabular}

ومتوسط الدخل الثهرى للأسرة حيث بلغت قيم معامل الارتباط ومن

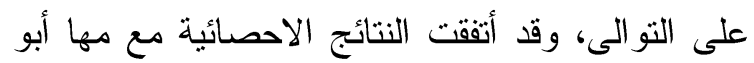
طالب (999 (1)) حيث أن المؤثرات الاقتصادية من أهم العو امل النى تؤثر على ممارسات الافر اد. كما وجدت علاقة ارتباطية عكسية معنوية عند

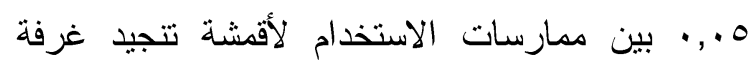
المعيشة وكلا من سن المبحوثات والحالة الاجتماعية

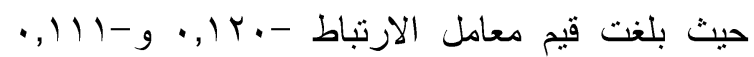
على التوالى، كما وجدت علاقة ارتباطية طردية معنوية

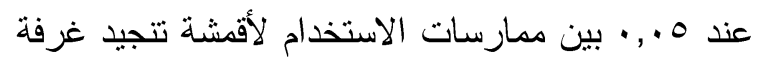

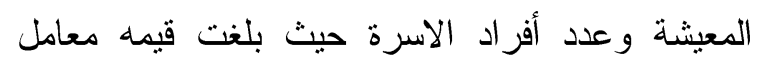

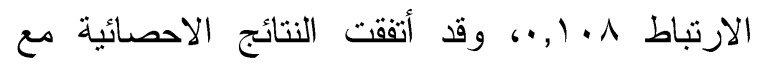

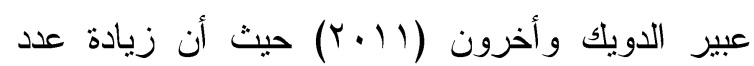
الأفر اد ترتفع الأعباء المعيشية و الضغوط و المسئوليات مما قد يجنب ربة الأسرة الاستخدام و العناية في أسلوب

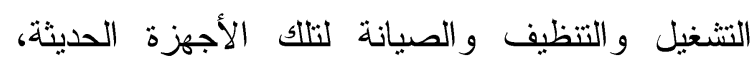
و هكذا يمكن رفض الفرض البحثى للاراسة جزئيا وقبولة جزئيا.
ثانيا: العلاقات الإرتباطية بين المتغيرات المستقلة و المتغير ات التابعة:

تم إستخدام معامل إرتباط الرتب سبيرمان و الإرتباط البسيط لبيرسون لتوضيح العلاقات الإرتباطية ولتحقيق

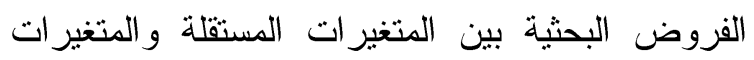

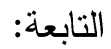

ه. العلاقات الارتباطية بين ممارسات الاستخدام

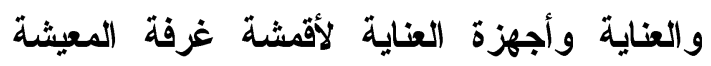
و الخصائص الاجتماعية والاقتصادية للمبحوثات: ولتحديد العلاقة الارتباطية بين ممارسات الاستخدام

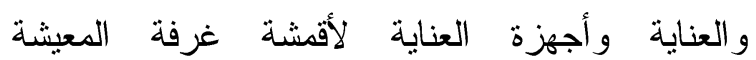
و الخصائص الاجتماعية والاقتصادية للمبحوثات تم اختبار الفرضية الاحصائية التالية لا توجد علاقة الاقدانة

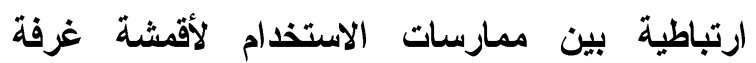

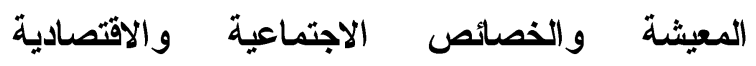
للمبحوثات ولايجاد العلاقات الارتباطية تم استخدام ارتباط الرتب سبيرمان والارتباط البسيط لبيرسون،

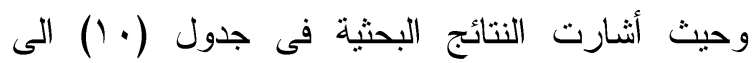

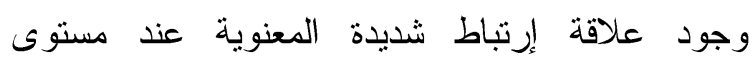
احتمالى (1 +, •) بين ممارسات الاستخدام لأقمشة غرفة

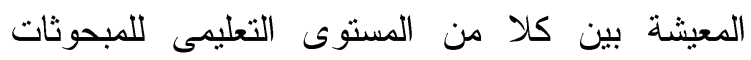

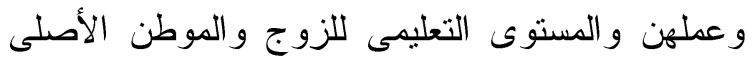


بين ممارسات طرق العناية لأقمشة تتجيد غرفة المعيشة

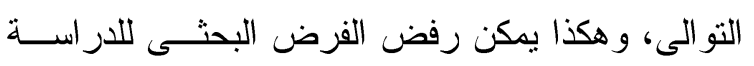
جزئيا وقبولة جزئيا. وتتفق النتائج البحثية دع عبيا. عبير الدويك وأخرون (Y (1) حيث أثنارت الى أن حجم الأسرة متغير مؤثز في والتعرف على كيفية التنظيف و العناية وصيانة تلك الك

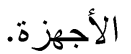

V. العلاقات الارتباطيــة بــين ممارســات الاســتخدام

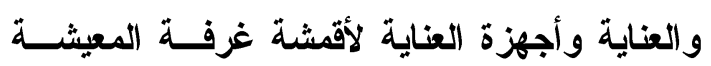
و الخصائص الاجتماعية والاقتصادية للمبحوثات: ولتحديد العلاقة الارتباطية بين ممارسات الاستخدام

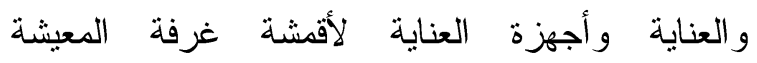
والخصائص الاجتماعية والاقتصادية للمبحوثات تم

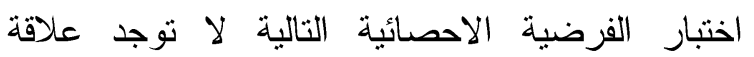

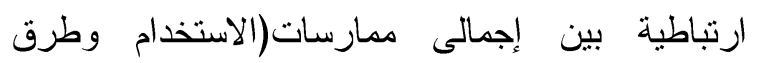

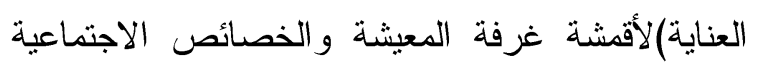
و الاقتصادية للمبحوثات و لايجاد العلاقات الارتباطية نم

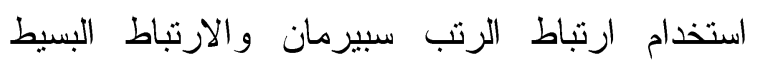

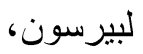

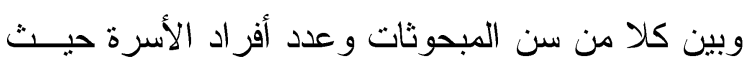

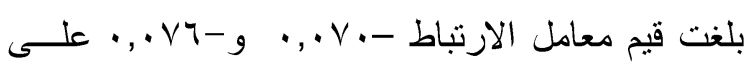

4. العلاقات الارتباطيـة بــين ممارســات الاســتخدام

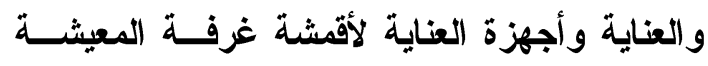
و الخصائص الاجتماعية والاقتصادية للمبحوثات: ولتحديد العلاقة الارتباطية بين ممارسات الاستخدام

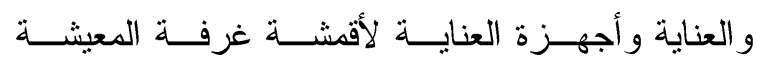

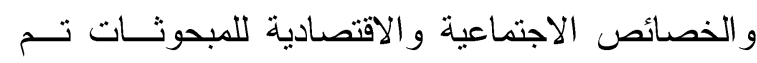

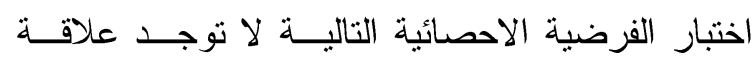

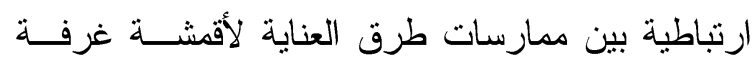

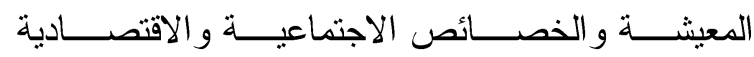

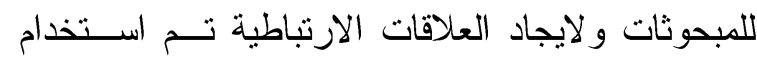

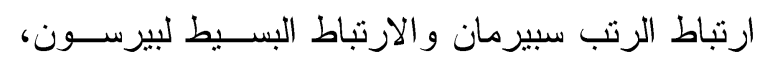

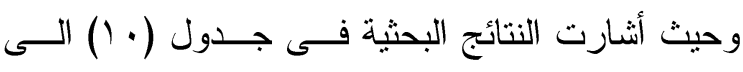

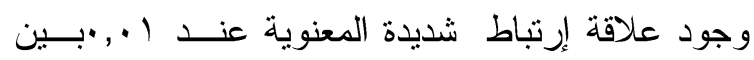
ممارسات طرق العناية لأقمشة تتجيد غرفـــة المعيشـــة

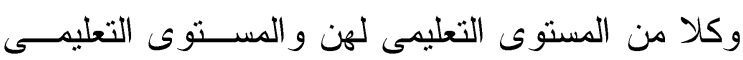

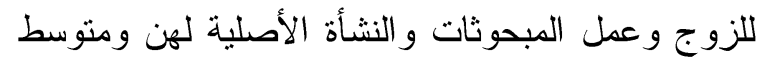

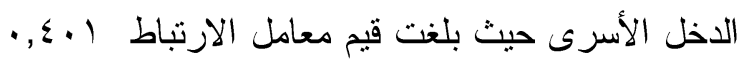

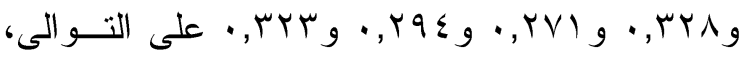

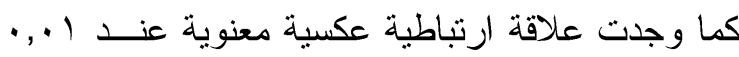
بين ممارسات طرق العناية لأقشة تتجيد غرفة المعيشة

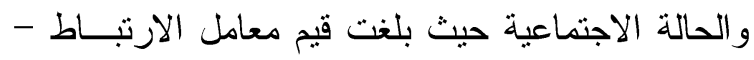

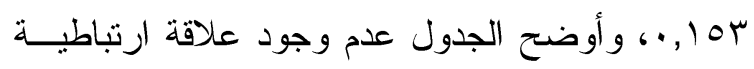

جدول · ا: يوضح العلاقات الإرتباطية بين المتفيرات المستقلة والمتفيرات التابعة

\begin{tabular}{|c|c|c|c|c|c|}
\hline معارف أجهزة العناية & الإجمالّى ممارسات & ممارسات العناية & ممارسات الإستخدام & والإقتصائص الإجتماعية & م \\
\hline$\cdot, \cdot \wedge r-$ & $* \cdot, 11 \leqslant-$ & $\cdot, \cdot V \cdot-$ & $*, I Y \cdot-$ & السن (r) & 1 \\
\hline$\cdot, .9 \leqslant-$ & $* *, Y \backslash 1-$ & $* *, 10 \%-$ & $*, 111-$ & الحالة الإجنماعية (r) & r \\
\hline$\cdot, \cdot 7 \varepsilon$ & $* *, \varepsilon \cdot 1$ & $* *, \varepsilon \cdot 1$ & $* *, r \circ V$ & المستوى التعليمى & $r$ \\
\hline., $.0 r$ & $* *, Y \vee Y$ & $* *, Y \vee I$ & $* *, Y \wedge$. & عمل المبحوثات & $\varepsilon$ \\
\hline$\cdot, \cdot$. & $* *, \mu r Y$ & $* *$, HYA & $* *, r \wedge \wedge$ & المستوى التعليمى للزو ج & 0 \\
\hline$\cdot, T \leqslant$ & $\cdot, \cdot 10$ & $\cdot, \cdot \vee \vee 7$ & $* \cdot, 1 \cdot 1$ & عدد أفراد الأسرة (r) & 1 \\
\hline., $.7 \varepsilon$ & $* *, Y \wedge \uparrow$ & $* *, Y 9 \leq$ & $* *, Y Y I$ & الموطن الأصلى & $\mathrm{V}$ \\
\hline , , , r & ***,rוr & ***,rYr & $* *, r \Gamma \cdot$ & مستوى دخل الأسرة (r) & $\Lambda$ \\
\hline \multicolumn{4}{|c|}{ (*) نتير الى أن القيمة المعنوية عند مستوى (0. . .) } & ير الى الارنباط البسيط(بيرسون) & \\
\hline \multicolumn{4}{|c|}{ 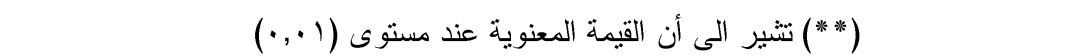 } & تير الى ارنباط الرتب(سبيرمان) & \\
\hline
\end{tabular}


قادرات عن غيرهن من ذوات التعليم المنخفض على

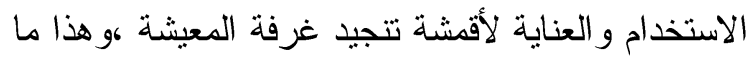

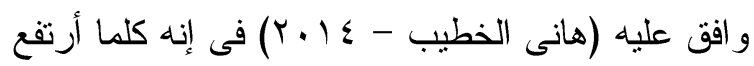
مستوى التعليم كلما أتسع الأفاق وزادت الهاب المعارف

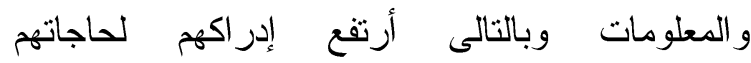

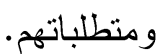

^. العلاقات الارتباطيـة بــين ممارســات الاســتخدام

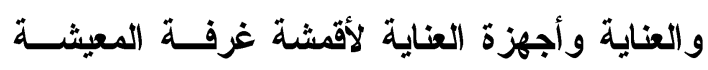
و الخصائص الاجتماعية والاقتصادية للمبحوثات: ولتحديد العلاقة الارنباطية بين ممارسات الاستخدام

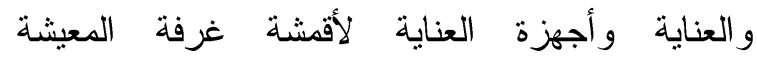
و الخصائص الاجتماعية والاقتصادية للمبحوثات تم تمانه اختبار الفرضية الاحصائية التالية لا توجد الهائه علاقة

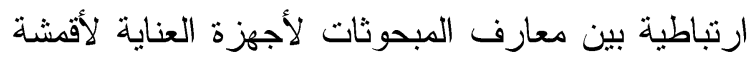
غرف المعيشة و الخصائص الاجتماعية والاقتصادية للمبحوثات و لايجاد العلاقات الارتباطية تم استخدام ارتباط الرتب سبيرمان والارنباط البسيط لبيرسون،

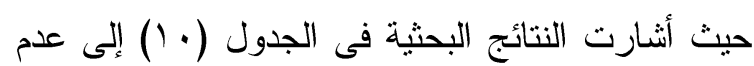
وجود علاقة ارتباطية بين معارف المبحوثات لأجهزة

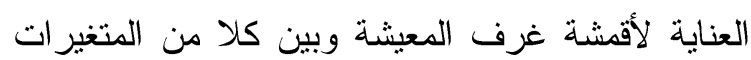
المستقلة، و هكذا يمكن قبول الفرض البحتى للار اسة.

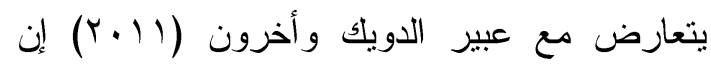
الإستخدام للمبحوثات لبعض الأجززة المنزلية الحديثة يؤثر فى بعض المتغيرات الاجتماعية والاقتصادية

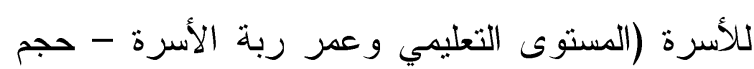
الأسرة و الاخل الكلي للأسرة).

\section{التوصيات}

ا. رفع الوعى نحو الأجهزة المنزلية المستخدمة فى

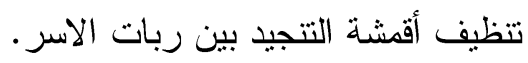

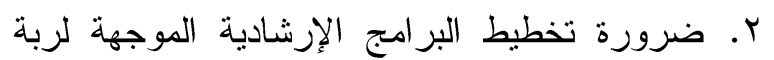

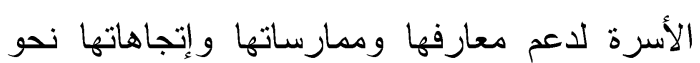

وحيث أنشارت النتائج البحثية فى جدول (•(1) الى وجود علاقة إرنباط شديدة المعنوية عند ال.,. بين

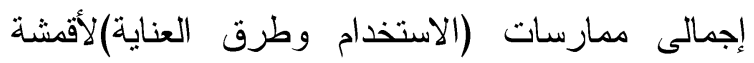
تتجيد غرفة المعيشة وكلا من المستوى التعليمى لهن الهن و المستوى التعليمى للزوج وعمل المبحوثات و الموطن الأصلى لهن ومتوسط الدخل الأسرى حيث بلغت قيم لـث

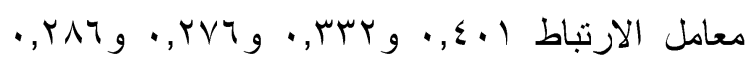

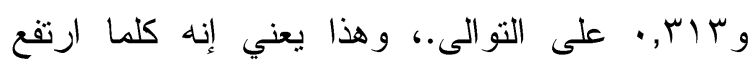

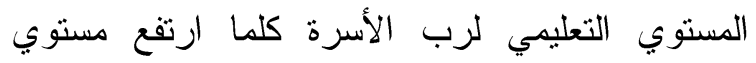
الوعي بتتسيق وتجميل المسكن، كما وجدت علاقة

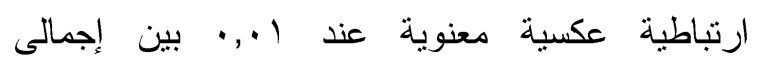
ممارسات (الاستخدام وطرق العناية)لأقمشة تتجيد غرفة

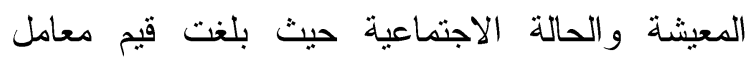

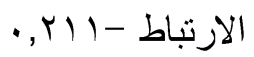
كما وجدت علاقة ارتباطية طردية معنوية عند ๑.,. بين إجمالى ممارسات (الاستخدام وطرق معند العناية)لأقمشة تتجيد غرفة المعيشة وكلا من عدد أفراد الاسرة وسن المبحوثات حيث بلغت قيمه معامل لئل

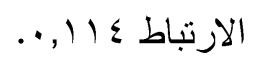

كما أوضح الجدول عدم وجود علاقة ارتباطية بين

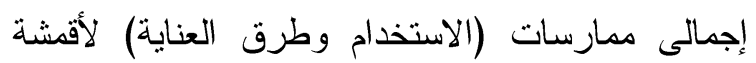
تتجيد غرفة المعيشة وعدد أفراد الأسرة حيث بلغت قيم

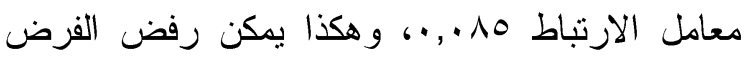

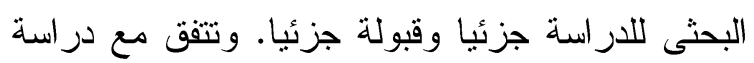

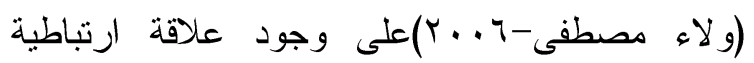
موجبة بين وعى ربة الاسرة بالاختبار و العناية

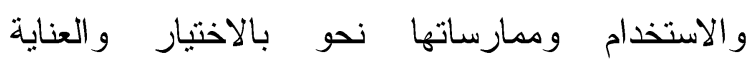
و الاستخدامبلانثاث و المفروشات، وترى الباحثة إنه مع ولئ

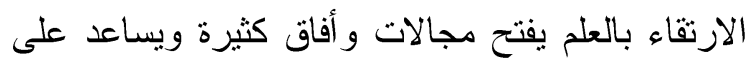

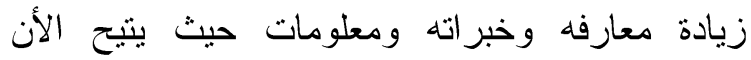
فرصة الاطلاع على المصادر المتنوعة من التليفزيون والأنترنت للتعرف على كل ما هو جديد وحديث ويفيدهم فى تتمية ادراكهن لكسايرة العصر وجعلهن 
شيماء أحمد نبوى توفيق (19 1 (r): "أسلوب اختيار

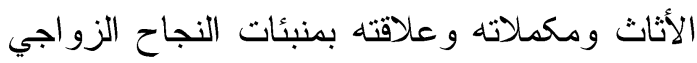

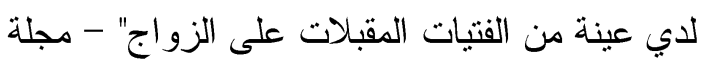

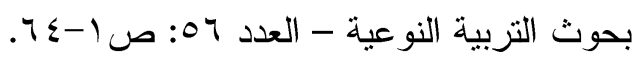
عبير محمود الدويك ومنار عبد الرحمن خضر لتهر

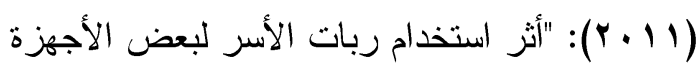
المنزلية الحديثة على دافعيتهن للإنجاز وكفاءتهن الأدائية والإنتاجية" - مجلة بحوث التربية النوعية - دائه

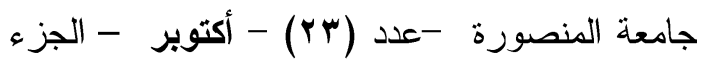
الثاني. عبير محمود الدويك ومهجة محمد مسلم(1 11 + ( ): دور ربة الأسرة في اختيار الأثاث و المفروشات ودمد وعلاقته

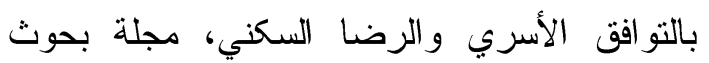

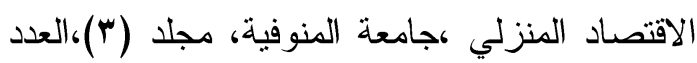

$$
\text { • }
$$

على عبد الغفار شعبر (1991 ) : "دراسة تحليلية للتحبيسات النسيجية فى التصميمات التتفيذية لأقمشة المفروشات" - المؤتمر المصرى الثالث للأقتصاد المنزلى - جامعة المنوفية- كلية الاقتصاد المنزلى

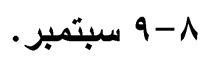

فاتن مصطفى كمال لطفى (19 999 1): "در اسة تأثيربعض

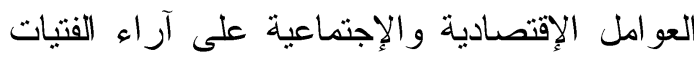

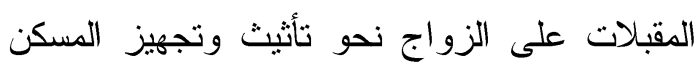

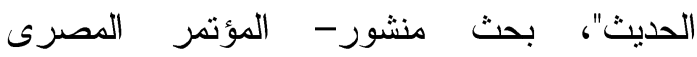

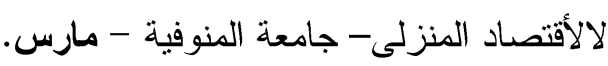

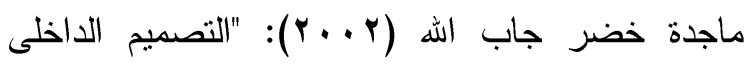
لفراغ المعيشة وعلاقتها ببعض العوامل الاسرية و السكنية" - مجلة الاسكندرية للتبادل العلمى- العدد

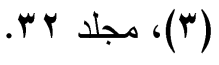

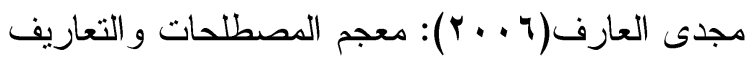
الفنية فى الصناعات النسيجية - صندوق دعم صناعة الغزل و المنسوجات - الطبعة الر ابعة.
الأجزة المنزلية المستخدمة فى تتظيف أقشة التتجيد. r. القيام بدراسات متخصصة فى سلوك ربات الاسر

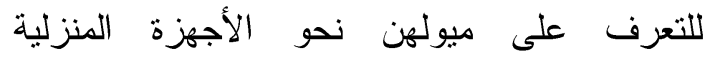
المستخدمة فى تتظيف أقششة التتجيد. ع. ضرورة نوفير كافة المعارف لربات الاسر نحو الأجززة المنزلية المستخدمة فى تنظيف أقمشة التجبيد المختلفة.

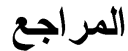

أحلام موسى محمد الطباخ(799 199): "علاقة البيئة السكنية بنمط شخصية المر اهق بمدينة الاسكندرية" - رسالة ماجستير - اقتصاد منزلي - كلية الزر اعة الفيه - جامعة الاسكندرية. دعاء عبد الرحمن محمد جودة (؟ . . ب): "المعايير

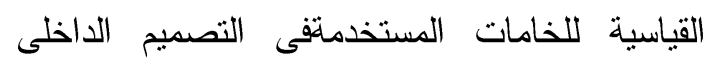
و الاثاث للمسكن بما بتو افق مع البيئة فى مصر" رسالة دكتور اه غير منشورة ،كلية الفنون التطبيقية، لينه

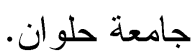
ذوقان عبيدات، عبد الرحمن عدس، كايد عبد الحق

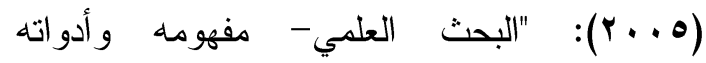
وأساليبه"، دار أسامة للنشر و التوزيع، جدة، طول، المملكة العربية السعودية.

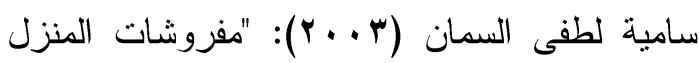
و الديكور الداخلى" دار القلم- دبى - الامارات العربية المتحدة.

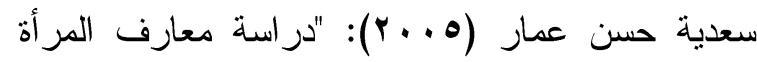
السعودية فى اختيار المفروشات المنزلية ومكملاتها

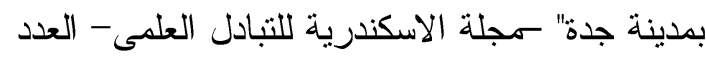

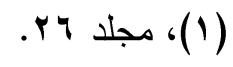

سونيا محمد شيبون (7 1 ـ ץ): "در اسة معارف الطالبات

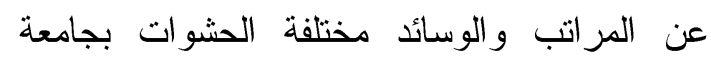
الإسكندرية"- مجلة الإسكندرية للعلوم الزراعية كلية الزر اعة- جامعة الإسكندرية- ديسمبر • 


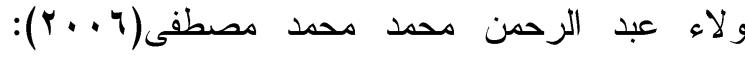

$$
\begin{aligned}
& \text { "وعى وممارسات ربة الاسرة نحو إختيار و استخدام }
\end{aligned}
$$

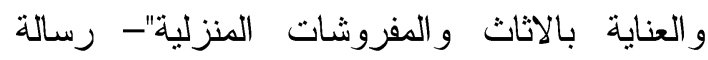

$$
\begin{aligned}
& \text { ماجستير غير منشورة- كلية الاقتصاد المنزلى بلى } \\
& \text { جامعة المنوفية. }
\end{aligned}
$$

Emre B. \& Nuray U. (2010): The Effect of Super Absorbent Fibers on the Washing, Dry Cleaning and Drying Behavior of Knitted Fabrics, Textile Journal, Vol 79, No 16.

Michael, J. Crosbic,(2001)"Standards for Building Types",Mc Graw -Hill Book Co. Singapore.

Vojta PJ, SP Randels, J Stout, M Muilenberg, HA Burge, H Lynn, H Mitchell, GT O'Connor, and DC Zeldin (2001)- "Effects of physical interventions on house dust mite allergen levels in carpet, bed, and upholstery dust in lowincome, urban homes". Environ Health Perspect, Aug; 109(8): 815-9.

Yiin LM, GG Rhoads, DQ Rich, J Zhang, Z Bai, JL Adgate, PJ Ashley, and PJ Lioy (2002) "Comparison of techniques to reduce residential lead dust on carpet and upholstery: the new jersey assessment of cleaning techniques trial." Environ Health Perspect, Dec 2002; 110(12): 1233-7.

"http://air.wikihow.com/ Mark Spelman (2019)

كيفية تتظيف الأثاث المنجد بجهاز التنظيف بالبخار" https://www.cosmictherap.com(2020)

$$
\text { "وسائل لتنظيف الأر ائك وطرق تطبيقها" }
$$

Copyright. All rights reserved. Theme by SuperbThemes WordPress Themes

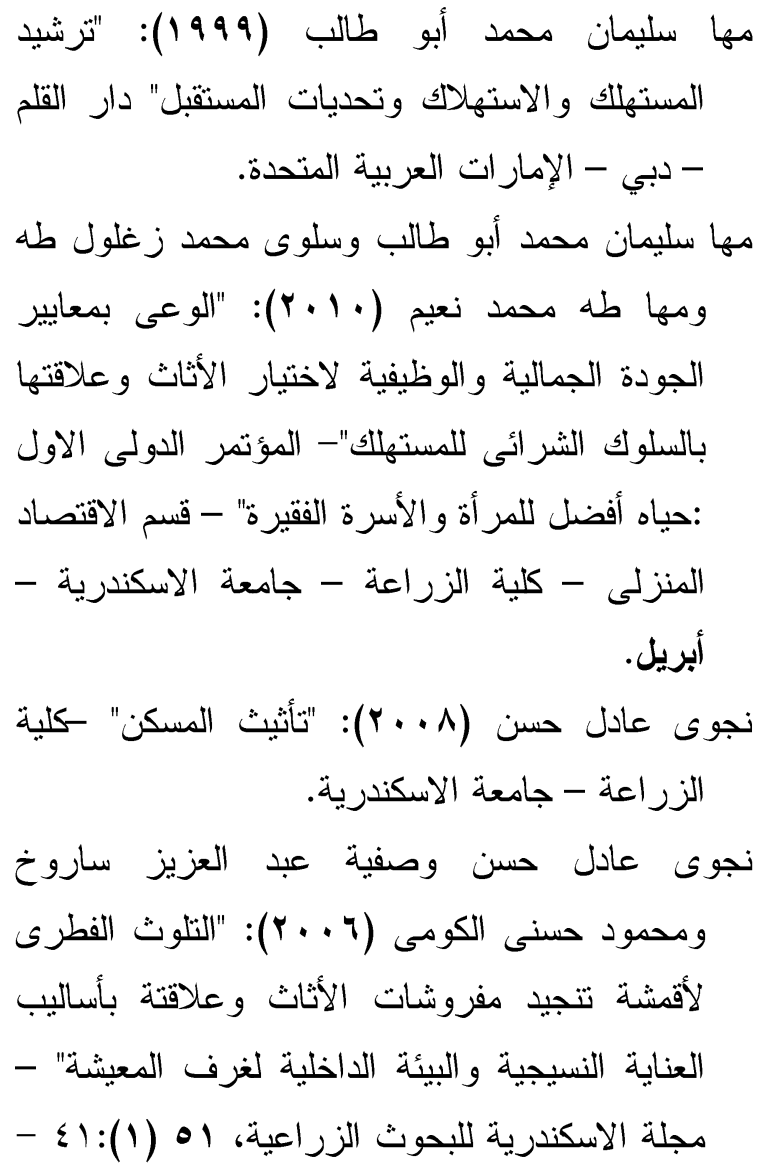




\title{
Use Practices and Methods of Care for Living Room Fabrics among A Sample of Women in Alexandria
}

\author{
Sonia Mohamed Abdel Mohsen Shaiboun \\ Clothing and Textile- Home Economics Department-Faculty of Agriculture-Alexandria University
}

\begin{abstract}
This research aimed to study the usage practices and methods of care for living room upholstery fabrics among a sample of women in Alexandria and the extent of their knowledge of modern devices for cleaning these fabrics. This study was conducted on a squamous sample of (360) female respondents in Alexandria. Where the data were collected using a questionnaire form in the personal interview, and the study relied on percentages, arithmetic mean, standard deviation, frequency, chi-square, and the simple correlation coefficient of Pearson and Spearman as statistical methods for presenting and discussing research results. The most important results were as follows:

1. The respondents prefer dark colors in the fabrics used for the living room at a rate of 58.9\%, and it was also found that they prefer the fabric of the living room to be made of velor by $37.5 \%$.

2. The low level of the respondents' practices of use, methods of care and total practices of living room upholstery fabrics, as well as the low level of their knowledge about appropriate care devices.

3. It was found that there is a significant correlation relationship at the probabilistic level $(0.01)$ between the total practices (use and methods of care) for the living room upholstery fabrics and both the marital status of the respondents, their educational level, the educational level of the husband, the respondents' work, their original home and the average household income, where the value of chi-square reached them, respectively $(29.06,83.52,65.79,31.85,31.36$, and 33.64).

4. It was also found that there is a correlation between each of the respondents' knowledge about care devices for upholstery fabrics for living rooms and the social status of the respondents, where the value of the chisquare for them reached 14.22 .

5. There is a highly significant correlation relationship at 0.01 between the total practices (use and care methods) of the living room upholstery fabrics and their educational level, husband's educational level, the respondents' work, their place of origin and average household income, where the correlation coefficient values were $0.401,0.332,0.276$ and 0.286 and 0.313 , respectively.

6. There was also a significant direct correlation at 0.05 between the total practices (use and care methods) of the living room upholstery fabrics and both the number of family members and the age of the respondents, where the value of the correlation coefficient was 0.114 .
\end{abstract}

